\title{
A New "Doctor and Patient" Optimization Algorithm: An Application to Energy Commitment Problem
}

\author{
Mohammad Dehghani ${ }^{1}{ }^{(D}$, Mohammad Mardaneh $\left.{ }^{1}{ }^{(}\right)$, Josep M. Guerrero ${ }^{2}{ }^{\circledR}$, \\ Om Parkash Malik ${ }^{3}$ (D) Ricardo A. Ramirez-Mendoza ${ }^{4} *(\mathbb{D})$, José Matas ${ }^{5}$ (D) Juan C. Vasquez ${ }^{2}$ (D) \\ and Lizeth Parra-Arroyo 4 \\ 1 Department of Electrical and Electronics Engineering, Shiraz University of Technology, \\ Shiraz 71557-13876, Iran; m.dehghani@sutech.ac.ir (M.D.); mardaneh@sutech.ac.ir (M.M.) \\ 2 CROM Center for Research on Microgrids, Department of Energy Technology, Aalborg University, \\ 9220 Aalborg, Denmark; joz@et.aau.dk (J.M.G.); juq@et.aau.dk (J.C.V.) \\ 3 Department of Electrical and Computer Engineering, University of Calgary, Calgary, AB T2N 1N4, Canada; \\ maliko@ucalgary.ca \\ 4 School of Engineering and Sciences, Tecnologico de Monterrey, 64849 Monterrey, Mexico; \\ A01036078@itesm.mx \\ 5 Electric Engineering Department, Polytechnic University of Catalonia (EEBE-UPC), 08019 Barcelona, Spain; \\ jose.matas@upc.edu \\ * Correspondence: ricardo.ramirez@tec.mx; Tel.: +52-81-2001-5597
}

Received: 24 July 2020; Accepted: 12 August 2020; Published: 21 August 2020

check for updates

\begin{abstract}
Regular assessments of events taking place around the globe can be a conduit for the development of new ideas, contributing to the research world. In this study, the authors present a new optimization algorithm named doctor and patient optimization (DPO). DPO is designed by simulating the process of treating patients by a physician. The treatment process has three phases, including vaccination, drug administration, and surgery. The efficiency of the proposed algorithm in solving optimization problems compared to eight other optimization algorithms on a benchmark standard test function with 23 objective functions is been evaluated. The results obtained from this comparison indicate the superiority and quality of DPO in solving optimization problems in various sciences. The proposed algorithm is successfully applied to solve the energy commitment problem for a power system supplied by a multiple energy carriers system.
\end{abstract}

Keywords: optimization; energy commitment (EC); doctor and patient optimization (DPO); power system; energy carriers; energy; unit commitment (UC)

\section{Introduction}

\subsection{Motivation}

Energy commitment (EC), the concept of choosing an adequate energy carrier operation, poses an important challenge in energy studies. Primary energy carriers are those that are extracted directly from natural resources, such as coal, oil, and natural gas, while secondary energy carriers are derived from primary energy [1]. In order to keep with the network's energy demand, energy carriers are optimized considering the technical and economical constraints [2]. In fact, EC is a constrained optimization problem that can be solved using optimization algorithms [3].

Optimization algorithms perform well in solving a variety of problems. In order to achieve the appropriate pattern of utilization of energy carriers, the EC problem was assessed using suitable optimization tools. 


\subsection{Contribution}

This paper proposes a new optimization algorithm named Doctor and Patient Optimizer (DPO) that obtains the optimal solution to an EC problem in power systems. The study aimed to achieve the following:

- Design and present a novel optimization algorithm named "Doctor and Patient" Optimization.

- Evaluate the proposed DPO algorithm on a set of benchmark test functions with 23 objective functions.

- Compare the efficiency of the DPO to eight other optimization algorithms.

- Study the EC issue on a standard energy grid with twenty-six power plants in different sectors of energy consumption (commercial, transportation, industrial, agriculture, residential, and public).

- Apply DPO to EC problem solving.

- Investigate the export and import of energy carriers in the EC problem.

- Investigate oil refining in the EC problem.

- Determine the appropriate pattern of energy carrier use to supply energy demand.

\subsection{Paper Structure}

The rest of paper is organized as follows. Section 2 reviews the studies conducted by the researchers. Section 3 introduces doctor and patient optimization, followed by the formulation of the energy commitment problem in Section 4. The benchmarking of DPO on twenty-three test functions and simulation of applying the proposed method on the EC problem is presented in Section 5, and, finally, conclusions are given in Section 6.

\section{Background}

Several research papers are published using different classical optimization algorithms to handle the optimization problem. The classical methods, such as the Lagrangian approach [4] Dynamic Programming (DP) [5] and Quadratic Programming (QP) [6], fail to optimize problems globally, which has led to the development of multiple new alternatives. Many heuristic and meta-heuristic optimization algorithms inspired by nature were developed in the search for alternatives.

New optimizing techniques inspired by major activities of living beings offer a wide range of problem-solving possibilities. Some are based on life style, movement patterns, or activities, like hunting, searching for food, etc. This has resulted in the development of many methods, such as in Reference [7], where the strategy for grey wolf optimization (GWO) was formulated based on the hunting of grey wolfs. Lion optimization algorithms (LOA) [8] were proposed based on the simulation of the lion life style; ant colony optimization (ACO) [9] was proposed based on movement pattern of ants; and donkey theorem optimization (DTO) [10] was presented based on behavior of donkeys searching for food. In general, optimization algorithms can be divided into four categories as physics-based, swarm-based, evolutionary-based, and game-based algorithms.

Physics-based algorithms are developed based on phenomena and laws of physics [11]. The Spring search algorithms (SSA) [12] is a physics-based algorithm which simulates Hooke's law. The Water cycle algorithms (WCA) [13] is proposed based on the natural event of the water follow cycle from rivers and streams into the sea. Gravitational search algorithms (GSA) [14] are based on gravitational force modeling between bodies. Some of the other algorithms that fall into this category are: simulated annealing (SA) [15], curved space optimization (CSO) [16], galaxy-based search algorithm (GbSA) [17], artificial chemical reaction optimization algorithms (ACROA) [18], central force optimization (CFO) [19], and small world optimization algorithms (SWOA) [20]. 
Swarm-based algorithms have been suggested based on collectives of living things. Particle swarm optimization (PSO) [21], derived from the bird group's social behavior during migration, is a common swarm-based algorithm. Another optimization process is the grasshopper optimization algorithm (GOA) [22] which simulates the grasshopper behavior. Marine predators algorithms (MPA) [23] are based on the biological interaction between predator and prey in the ocean. Some of the other algorithms that fall into this category are: grey wolf optimization (GWO) [7], lion optimization algorithm (LOA) [8], ant colony optimization (ACO) [9], donkey theorem optimization (DTO) [10], cuckoo search (CS) [24], artificial bee colony (ABC) [25], ant lion optimizer (ALO) [26], whale optimization algorithm (WOA) [27], and bat inspired algorithm (BA) [28].

Evolutionary-based algorithms use biologically based processes, such as mutation, reproduction, selection, and recombination. Genetic algorithm (GA) [29] is the most famous type of algorithm in this category and is based on the theory of Darwinian evolution. Some other algorithms in this category are: evolution strategy (ES) [30], differential evolution (DE) [31], biogeography-based optimizer (BBO) [32], and genetic programming (GP) [33].

Game-based algorithms have introduced new optimization techniques by simulating rules of different games. The dice game optimizer (DGO) [34] is a game-based algorithm that has been proposed based on the rules governing the game of dice and the impact the players have on each other. Another algorithm in this category is the orientation search algorithm (OSA) [35] that has been inspired by the game of orientation in which players move in the direction of a referee. Shell game optimization (SGO) [36] is a game-based algorithm proposed which is based on a simulation of the rules of the shell game.

Energy commitment (EC) sets the best template for using energy carriers because the technical limitations are dealt with first and the economic challenges after. Adjusting energy carriers to the highest demand would be unnecessary and costly. Indeed, energy carriers should be used optimally, as the proper management of energy resources can save considerable money. First, the energy demand must be determined in the EC issue. Similar to the unit commitment (UC) problem, this energy demand could span $24 \mathrm{~h}$. In the UC issue, the demand for electricity must be fulfilled with the appropriate unit combination for every hour of the study.

UC involves adjusting thermal generators in order to meet the projected demand and minimize the cost of system operation [37]. UC is accountable in the selection of the units which can be set to operate economically [38]. UC also contributes to the power calculation of each unit based on total demand [39]. In power systems, it is important to create a table of optimum generating units with minimum fuel and transaction costs corresponding to the load requirements [40]. In order to solve the UC problem, both intelligent and classical techniques have been proposed [41]. a mixed-integer linear programming (MILP) model to figure out the transmission-constrained direct current (DC)-based unit commitment (UC) problem using the generalized generation distribution factors (GGDF) for modeling the transmission network constraints is proposed in Reference [42]. Intelligent techniques are an important choice in the engineering field due to their ability to optimize multi-range local optimal points [43]. The memetic binary differential evolution algorithm (MDPE) has been proposed to solve a profit-based UC problem [44]. An uncertain UC problem study is suggested in the presence of energy storage systems using list-based genetic algorithm-priority [45]. Quantum binary particle swarm optimization (QBPSO) algorithms are proposed to reduce operation cost in the UC problem [46]. Other algorithms, such as the whale optimization algorithm (WOA) [47], gray wolf algorithm (GWO) [48], shuffled frog-leaping algorithm [49], improved genetic algorithm [50], and simulated annealing [51], have also been suggested to find the solution of UC problem. The various studies in operation of power systems, such as energy reservation review [52], energy storage systems [53], and the impact of renewable energy sources [54], are analyzed by researchers. 


\section{Doctor and Patient Optimization (DPO)}

In this section, the Doctor and Patient Optimization (DPO) algorithm is introduced to solve optimization problems. DPO are designed using simulation of patients' treatment steps. The proposed algorithm has three phases, including: (a) vaccination, (b) drug administration, and (c) surgery. This process is such that population is vaccinated first to prevent infection. In the second phase, appropriate medication is prescribed to treat patients. Finally, in the third phase, surgery is performed on patients with a serious condition.

\subsection{Mathematical Modeling}

The population in DPO are patients who need to be treated by a doctor. This population of patients is specified in Equation (1).

$$
P=\left[\begin{array}{c|ccccc}
P_{1} & p_{1}^{1} & \cdots & \cdots & \cdots & p_{1}^{m} \\
\vdots & \vdots & \ddots & \vdots & & \vdots \\
P_{i} & p_{i}^{1} & \cdots & p_{i}^{d} & \cdots & p_{i}^{m} \\
\vdots & \vdots & & \vdots & \ddots & \vdots \\
P_{N} & p_{N}^{1} & \cdots & \cdots & \cdots & p_{N}^{m}
\end{array}\right]
$$

where $P$ is the patients population, $P_{i}$ is the $i$ th patient, $p_{i}^{d}$ is the $d$ th feature of $i$ th patient, $N$ is the number of patient (population), and $m$ is the number of variables.

This population is treated and updated in three phases. The required information in this process is calculated by Equations (2)-(5).

$$
\begin{gathered}
\text { dosage }_{i}=2-\frac{F_{i}^{n}}{F_{\text {best }}^{n}}, \\
F_{i}^{n}=\frac{f_{\text {it }}-f_{\text {worst }}}{\sum_{j=1}^{N}\left(\text { fit }_{j}-f_{\text {worst }}\right)}, \\
f_{\text {worst }}=\max (\text { fit }) \& P_{\text {worst }}=P\left(\text { location }\left(f_{\text {worst }}\right)\right), \\
f_{\text {best }}=\min (\text { fit }) \& P_{\text {best }}=P\left(\text { location }\left(f_{\text {best }}\right)\right) .
\end{gathered}
$$

Here, $\operatorname{dosage}_{i}$ is the dosage of vaccine or drug for $i$ th patient, $F_{i}^{n}$ is the normalized fitness of $i$ th patient, $F_{\text {best }}^{n}$ is the normalized fitness of best patient, $f_{\text {worst }}$ is the fitness function of worst patient, $f_{\text {best }}$ is the fitness function of best patient, $P_{\text {worst }}$ is the position of worst patient, and $P_{\text {best }}$ is the position of best patient.

\subsubsection{Phase A: Vaccination}

An important step in the community health process is vaccination. This phase is simulated by Equations (6) and (7).

$$
\begin{aligned}
& V_{i}^{d}=\operatorname{rand} \times\left(\text { dosage }_{i} \times p_{i}^{d}-p_{\text {worst }}^{d}\right), \\
& V_{i}^{d}=\operatorname{rand} \times\left(\text { dosage }_{i} \times p_{i}^{d}-p_{\text {worst }}^{d}\right) .
\end{aligned}
$$

Here, $V_{i}^{d}$ is the $d$ th dimension of vaccine for $i$ th patient, rand is a random number in the interval $[0-1]$, and $p_{\text {worst }}^{d}$ is the $d$ th dimension of worst patient. 


\subsubsection{Phase B: Drug Administration}

In this phase of the patient treatment process, the doctor prescribes each patient pharmaceuticals according to the patient's condition. Drug administration is simulated by Equations (8) and (9).

$$
\begin{aligned}
& d_{i}^{d}=\operatorname{rand} \times\left(p_{\text {best }}^{d}-\text { dosage }_{i} \times p_{i}^{d}\right), \\
& P_{i}=\left\{\begin{array}{c}
P_{i}+d_{i}, \text { fit }\left(P_{i}+d_{i}\right) \leq f i t_{i} \\
P_{i}, \text { else }
\end{array}\right.
\end{aligned}
$$

Here, $d_{i}^{d}$ is the $d$ th dimension of a drug for the $i$ th patient, and $p_{b e s t}^{d}$ is the $d$ th dimension of best patient.

\subsubsection{Phase C: Surgery}

Vaccination and medication are not enough for patients with serious conditions. In such cases, the patient's condition will improve with surgery. This phase of treatment is modeled by Equation (10).

$$
P_{i}=\left\{\begin{array}{cl}
0.6 \times P_{i}+0.4 \times P_{\text {best }}, & F_{\text {best }}^{n}-F_{i}^{n} \geq 0.9 F_{\text {best }}^{n} . \\
P_{i}, & \text { else }
\end{array}\right.
$$

\subsection{Implementation of $D P O$}

After designing the proposed DPO algorithm, it can be used to solve optimization problems. Implementation of DPO is expressed in Algorithm 1.

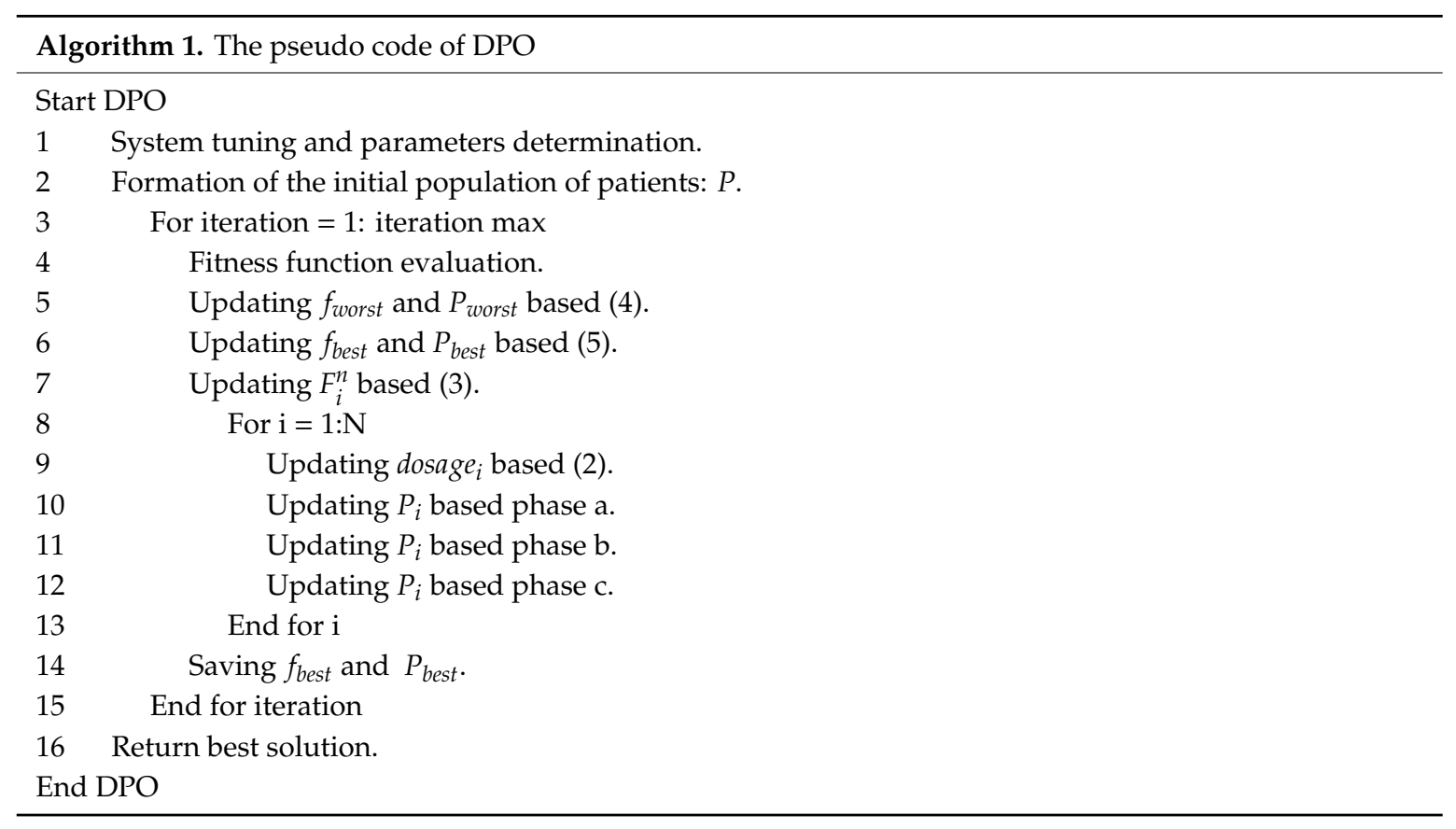




\section{Energy Commitment (EC) Problem}

The EC analysis should be performed in a suitable area, such as the energy grid, which includes the public, commercial, residential, industrial, agricultural, and transportation sectors.

In the energy grid, the energy demand is determined as the sum of the demand in the various grid subdivisions using Equation (11).

$$
E C_{f}=E C_{1}+E C_{2}+\ldots+E C_{N}=\sum_{i=1}^{N} E C_{i},
$$

where $E C_{f}$ is the total energy demand, $E C_{i}$ is the energy demand of the $i$-th sector of grid, and $N$ is the number of different sectors of the energy grid.

In various sectors, the energy consumption is expressed in Equation (12):

$$
E_{1}=\left[E C_{1} E C_{2} \ldots E C_{i} \ldots E C_{N}\right]^{T} .
$$

Here, $E_{1}$ is the energy demand matrix in the various energy sectors.

Final energy consumption based on different energy carriers is determined by Equation (13):

$$
E_{2}=T_{1,2} \times E_{1}
$$

where $E_{2}$ is the final energy consumption based on different energy carriers, and $T_{1,2}$ is the transform matrix of different energy sectors to different energy carriers.

Energy loss is modeled using Equation (14).

$$
E_{3}=T_{2,3} \times E_{2}
$$

Here, $E_{3}$ is the final energy consumption based on different energy carriers considering losses, and $T_{2,3}$ is the efficiency matrix.

Input fuels to generation unit in order to electrical energy demand supply are calculated by Equations (15) and (16).

$$
\begin{gathered}
E_{u}=T_{u} \times E_{e}, \\
E_{e_{1}}=T_{u, f} \times E_{u},
\end{gathered}
$$

where $E_{u}$ is the value of generation of different units, $T_{u}$ is the separation matrix of electricity generated by different units that is specified by UC solving, $E_{e}$ is the total electrical energy demand, $E_{e_{1}}$ is the input fuel to different units, and $T_{u, f}$ is the unit efficiency matrix.

The input of energy carriers to the units are calculated by Equation (17).

$$
E_{e_{2}}=T_{f, c} \times E_{e_{1}},
$$

where $E_{e_{2}}$ is the value of energy carriers for electricity generation, and $T_{f, c}$ is the conversion matrix of input fuel to energy carriers.

In this stage after conversion of electrical energy demand to source energy carriers, final energy consumption is calculated using Equation (18).

$$
E_{4}=E_{3}+E_{e_{2}}-E_{e}
$$

$E_{4}$ is the final energy consumption after converting electrical energy demand to an input from energy carriers to units. 
At this stage, Equation (19) is used to simulate the process of refining crude oil.

$$
E_{p_{1}}=T_{p} \times E_{p}
$$

Here, $E_{p_{1}}$ represents the energy carriers produced by refining the oil, $T_{p}$ is the separation matrix of products produced from the refining process, and $E_{p}$ is the maximum capacity of refineries.

Final energy consumption considering the refining crude oil process is determined using Equation (20).

$$
E_{5}=E_{4}+E_{p}-E_{p_{1}}
$$

Here, $E_{5}$ is the final energy consumption after refining crude oil. Actually $E_{5}$ determines energy carriers to supply energy demand.

Finally, the import and export of energy carriers is determined using Equation (21).

$$
E_{6}=E_{5}-P,
$$

where $P$ is the domestic production of energy carriers, and $E_{6}$ is import and/or export of energy carriers. In $E_{6}$, a negative sign denotes an export, while a positive sign means the import of energy carriers.

\section{Simulation Study and Discussion}

\subsection{Case Study A: Benchmark Test Functions}

In this section, the performance of DPO is evaluated on a standard set of benchmark test functions which have been used by the researchers in various earlier studies [55,56]. These benchmark functions includes twenty-three test functions that are categorized into Unimodal [57,58], Multimodal [58,59], and Fixed-dimension Multimodal [58] functions. The description of these test functions is found in Appendix A and in Tables A1-A3.

\subsubsection{Experimental Setup}

The performance of the DPO is compared with the following eight optimization algorithms: Genetic Algorithm (GA) [60], Particle Swarm Optimization (PSO) [61], Gravitational Search Algorithm (GSA) [14], Teaching Learning Based Optimization (TLBO) [62], Grey Wolf Optimizer (GWO) [7], Grasshopper Optimization Algorithm (GOA) [22], Whale Optimization Algorithm (WOA) [27], and Marine Predators Algorithm (MPA) [23].

The proposed algorithm is implemented 30 times for each benchmark test function to obtain the average ( $a v g)$, standard deviation (std), best, and worst values. In each run, the number of maximum iterations performed is fixed at 1000 for all the twenty-three benchmark test functions. The population size $(N)$ is fixed at 50 . The algorithm is implemented in MATLAB R2017b version using a 64 -bit Core i7 processor with $3.20 \mathrm{GHz}$ and $16 \mathrm{~GB}$ main memory.

\subsubsection{Benchmarking Results of Unimodal Test Function}

This group of functions is used to evaluate the exploitation ability of algorithms. The results of the implementation of the DPO and other mentioned algorithms on these test functions are presented in Table 1 . DPO is clearly superior to all other compared algorithms in all $F_{1}$ to $F_{7}$ test functions. 
Table 1. Optimization results on unimodal test functions.

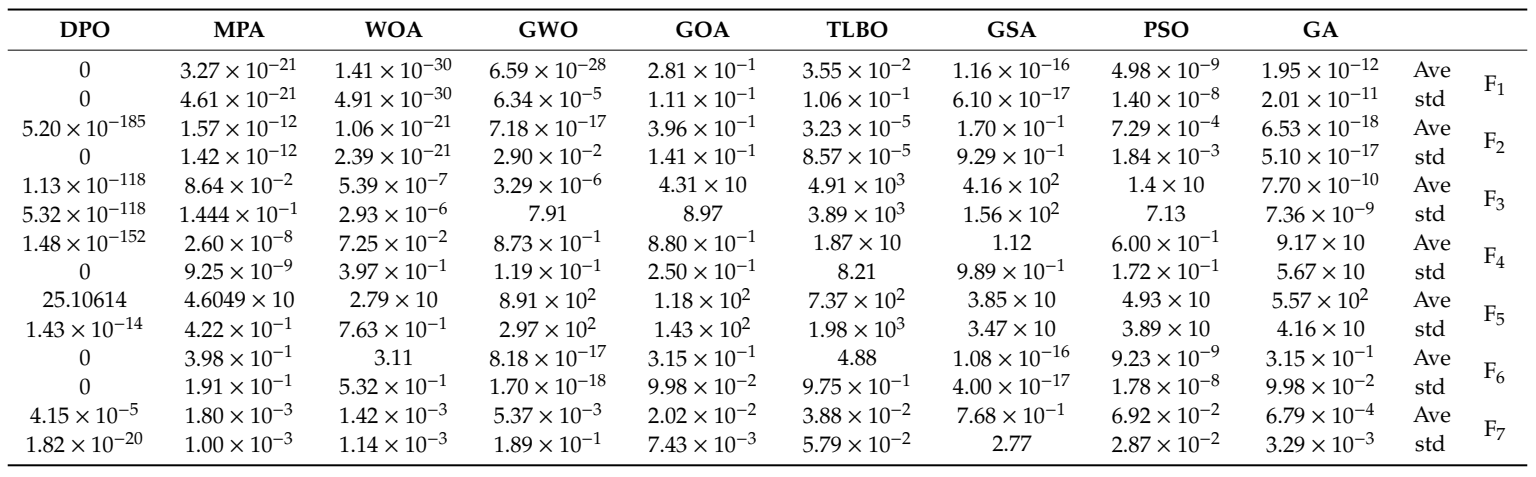

\subsubsection{Benchmarking Results of Multimodal Test Function}

In this type of test functions, the number of local solutions are increased exponentially with the increasing dimensions of functions. As a result, it is very difficult to achieve the optimal response in this type of test functions. Table 2 shows the results of implementing and comparing the proposed algorithm and other eight optimization algorithms on this group of test functions, including $F_{8}$ to $F_{13}$.

Table 2. Optimization results on multimodal test functions.

\begin{tabular}{|c|c|c|c|c|c|c|c|c|c|c|}
\hline DPO & MPA & WOA & GWO & GOA & TLBO & GSA & PSO & GA & & \\
\hline-8548.93 & $-8.36 \times 10^{2}$ & $-5.10 \times 10^{2}$ & $-6.12 \times 10$ & $-6.92 \times 10^{2}$ & $-3.81 \times 10^{2}$ & $-2.75 \times 10^{2}$ & $-5.01 \times 10^{2}$ & $-5.11 \times 10^{2}$ & Ave & \\
\hline $8.13 \times 10^{-13}$ & $8.11 \times 10^{2}$ & $6.95 \times 10^{2}$ & $3.94 \times 10$ & $9.19 \times 10$ & $2.83 \times 10$ & $5.72 \times 10$ & $4.28 \times 10$ & $4.37 \times 10$ & std & $\mathrm{F}_{8}$ \\
\hline 0 & 0 & 0 & $3.10 \times 10^{-1}$ & $1.01 \times 10^{2}$ & $2.23 \times 10$ & $3.35 \times 10$ & $1.20 \times 10^{-1}$ & $1.23 \times 10$ & Ave & $\mathrm{F}_{2}$ \\
\hline $4.44 \times 10^{-15}$ & $9.69 \times 10^{-12}$ & 7.40 & $1.06 \times 10^{-13}$ & 1.15 & $1.55 \times 10$ & $8.25 \times 10^{-9}$ & $5.20 \times 10^{-11}$ & $5.31 \times 10^{-11}$ & Ave & \\
\hline $7.06 \times 10^{-31}$ & $6.13 \times 10^{-12}$ & 9.89 & $4.34 \times 10^{-2}$ & $7.87 \times 10^{-1}$ & 8.11 & $1.90 \times 10^{-9}$ & $1.08 \times 10^{-10}$ & $1.11 \times 10^{-10}$ & std & $\mathrm{F}_{10}$ \\
\hline 0 & 0 & $2.89 \times 10^{-4}$ & $2.49 \times 10^{-3}$ & $5.74 \times 10^{-1}$ & $3.01 \times 10^{-1}$ & 8.19 & $3.24 \times 10^{-6}$ & $3.31 \times 10^{-6}$ & Ave & $F_{1}$ \\
\hline $9.31 \times 10^{-18}$ & $5.20 \times 10^{-3}$ & $2.14 \times 10^{-1}$ & $6.23 \times 10^{-2}$ & 1.02 & $2.47 \times 10^{2}$ & $3.14 \times 10^{-1}$ & $4.77 \times 10^{-7}$ & $4.88 \times 10^{-7}$ & std & $\mathrm{F}_{12}$ \\
\hline $7.44 \times 10^{-1}$ & $9.90 \times 10^{-1}$ & 1.89 & $6.54 \times 10^{-1}$ & $6.60 \times 10^{-2}$ & $2.81 \times 10^{2}$ & 5.73 & $8.26 \times 10^{-1}$ & $9.39 \times 10^{-1}$ & Ave & \\
\hline $6.95 \times 10^{-16}$ & $1.93 \times 10^{-1}$ & $2.66 \times 10^{-1}$ & $4.47 \times 10^{-3}$ & $4.33 \times 10^{-2}$ & $8.63 \times 10^{2}$ & 8.95 & $4.39 \times 10^{-2}$ & $4.49 \times 10^{-2}$ & std & $\mathrm{F}_{13}$ \\
\hline
\end{tabular}

\subsubsection{Benchmarking Results of Fixed-Dimension Multimodal Test Function}

The characteristic of this group of objective functions is the low number of local responses and dimensions. The results of the evaluation and optimization of these objective functions are given in Table 3. The ability of DPO to access the optimal answer is evident compared to other algorithms.

Table 3. Optimization results on multimodal test functions with low dimension.

\begin{tabular}{|c|c|c|c|c|c|c|c|c|c|c|}
\hline DPO & MPA & WOA & GWO & GOA & TLBO & GSA & PSO & GA & & \\
\hline $9.98 \times 10^{-1}$ & $9.98 \times 10^{-1}$ & $2.11 \times 10$ & $1.26 \times 10$ & $9.98 \times 10$ & $6.79 \times 10$ & $3.61 \times 10$ & $2.77 \times 10$ & $4.39 \times 10$ & Ave & \\
\hline $1.02 \times 10^{-15}$ & $2.47 \times 10^{-13}$ & $2.49 \times 10$ & $6.86 \times 10^{-1}$ & $9.14 \times 10^{-1}$ & $1.12 \times 10$ & $2.96 \times 10$ & $2.32 \times 10$ & $4.41 \times 10^{-2}$ & std & $\mathrm{F}_{14}$ \\
\hline $3.11 \times 10^{-4}$ & $8.21 \times 10^{-3}$ & $3.66 \times 10^{-3}$ & $1.01 \times 10^{-2}$ & $7.15 \times 10^{-2}$ & $5.15 \times 10^{-2}$ & $6.84 \times 10^{-2}$ & $9.09 \times 10^{-3}$ & $7.36 \times 10^{-2}$ & Ave & \\
\hline$-1.03 \times 10$ & $-1.02 \times 10$ & $-1.02 \times 10$ & $-1.02 \times 10$ & $-1.02 \times 10$ & $-1.01 \times 10$ & $-1.02 \times 10$ & $-1.02 \times 10$ & $-1.02 \times 10$ & Ave & \\
\hline $3.97 \times 10^{-16}$ & $4.46 \times 10^{-16}$ & $7.02 \times 10^{-9}$ & $3.23 \times 10^{-5}$ & $4.74 \times 10^{-8}$ & $3.64 \times 10^{-8}$ & $0.00 \times 10$ & $0.00 \times 10$ & $4.19 \times 10^{-7}$ & std & 16 \\
\hline $3.98 \times 10^{-1}$ & $3.98 \times 10^{-1}$ & $3.98 \times 10^{-1}$ & $3.98 \times 10^{-1}$ & $3.98 \times 10^{-1}$ & $3.98 \times 10^{-1}$ & $3.98 \times 10^{-1}$ & $3.98 \times 10^{-1}$ & $3.98 \times 10^{-1}$ & Ave & \\
\hline $8.94 \times 10^{-16}$ & $1.95 \times 10^{-15}$ & $7.16 \times 10^{-6}$ & $2.25 \times 10^{-5}$ & $1.48 \times 10$ & $1.94 \times 10^{-10}$ & $3.24 \times 10^{-2}$ & $6.59 \times 10^{-5}$ & $6.33 \times 10^{-7}$ & std & \\
\hline$-3.86 \times 10$ & $-3.86 \times 10$ & $-3.84 \times 10$ & $-3.75 \times 10$ & $-3.77 \times 10$ & $-3.73 \times 10$ & $-3.86 \times 10$ & $-3.80 \times 10$ & $-3.81 \times 10$ & Ave & \\
\hline $2.68 \times 10^{-15}$ & $2.42 \times 10^{-7}$ & $1.57 \times 10^{-3}$ & $2.55 \times 10^{-3}$ & $3.53 \times 10^{-7}$ & $9.69 \times 10^{-4}$ & $4.15 \times 10^{-1}$ & $3.37 \times 10^{-15}$ & $4.37 \times 10^{-10}$ & std & \\
\hline$-3.32 \times 10$ & $-3.32 \times 10$ & $-2.98 \times 10$ & $-2.84 \times 10$ & $-3.23 \times 10$ & $-2.17 \times 10$ & $-1.47 \times 10$ & $-3.32 \times 10$ & $-2.39 \times 10$ & Ave & \\
\hline $1.29 \times 10^{-15}$ & $1.14 \times 10^{-11}$ & $3.76 \times 10^{-1}$ & $3.71 \times 10^{-1}$ & $5.37 \times 10^{-2}$ & $1.64 \times 10^{-1}$ & $5.32 \times 10^{-1}$ & $2.66 \times 10^{-1}$ & $4.37 \times 10^{-1}$ & std & \\
\hline$-10.15 \times 10$ & $-8.11 \times 10$ & $-7.05 \times 10$ & $-2.28 \times 10$ & $-7.38 \times 10$ & $-7.33 \times 10$ & $-4.57 \times 10$ & $-7.54 \times 10$ & $-5.19 \times 10$ & Ave & \\
\hline
\end{tabular}




\subsection{Case Study B: EC Problem}

In this section, after implementing the DPO on benchmark test function and showing its strong ability in solving optimization problems, the proposed optimization algorithm is applied to the EC problem to determine the appropriate pattern of use of energy carriers.

The EC is implemented on an energy network with 26 power plants for a 24 -h study period. The energy network included residential, commercial, public, industrial, transportation, and agriculture sectors and is supplied by various energy carriers. The energy demand in this network is shown for different sections in Table 4. The profile of this energy demand is displayed intuitively in Figure 1 . All the other information surrounding the energy network is supplied in Appendix B and in Tables A8-A10. The MBOE (millions of barrels of oil equivalent) unit is applied as the energy unit in this paper.

Table 4. Final energy consumption (barrels of oil equivalent (BOE)).

\begin{tabular}{ccccccccc}
\hline Hour & 1 & 2 & 3 & 4 & 5 & 6 & 7 \\
\hline Residential, Commercial, and Public & 4609.373 & 4690.715 & 4582.259 & 4609.373 & 4744.943 & 5016.082 & 5422.792 & 6588.692 \\
Industrial & 2169.252 & 2207.533 & 2156.492 & 2169.252 & 2233.054 & 2360.657 & 2552.062 & 3100.755 \\
Transportation & 2931.142 & 2982.868 & 2913.9 & 2931.142 & 3017.352 & 3189.772 & 3448.402 & 4189.808 \\
Agriculture & 384.9789 & 391.7726 & 382.7143 & 384.9789 & 396.3018 & 418.9476 & 452.9163 & 550.2934 \\
Other & 28.81579 & 29.3243 & 28.64628 & 28.81579 & 29.66331 & 31.35835 & 33.90092 & 41.18962 \\
Non-Energy & 983.1946 & 1000.545 & 977.4111 & 983.1946 & 1012.112 & 1069.947 & 1156.7 & 1405.39 \\
\hline Hour & 9 & 10 & 11 & 12 & 13 & 14 & 15 \\
\hline Residential, Commercial, and Public & 6886.946 & 7049.629 & 7239.427 & 7022.515 & 7022.515 & 6914.06 & 7103.857 & 7185.199 \\
Industrial & 3241.118 & 3317.68 & 3407.002 & 3304.92 & 3304.92 & 3253.879 & 3343.201 & 3381.482 \\
Transportation & 4379.471 & 4482.923 & 4603.617 & 4465.681 & 4465.681 & 4396.713 & 4517.407 & 4569.133 \\
Agriculture & 575.2038 & 588.7913 & 604.6433 & 586.5267 & 586.5267 & 577.4683 & 593.3204 & 600.1142 \\
Other & 43.05417 & 44.0712 & 45.25773 & 43.9017 & 43.9017 & 43.22368 & 44.41021 & 44.91872 \\
Non-Energy & 1469.008 & 1503.709 & 1544.194 & 1497.926 & 1497.926 & 1474.792 & 1515.276 & 1532.627 \\
\hline Hour & 17 & 18 & 19 & 20 & 21 & 22 & 23 \\
\hline Industrial & 6914.06 & 6859.832 & 6778.49 & 6914.06 & 7049.629 & 6724.262 & 5965.071 & 4988.968 \\
Transportation & 3253.879 & 3228.358 & 3190.077 & 3253.879 & 3317.68 & 3164.556 & 2807.268 & 2347.897 \\
Agriculture & 4396.713 & 4362.229 & 4310.503 & 4396.713 & 4482.923 & 4276.018 & 3793.242 & 3172.53 \\
Other & 577.4683 & 572.9392 & 566.1454 & 577.4683 & 588.7913 & 561.6163 & 498.208 & 416.683 \\
Non-Energy & 43.22368 & 42.88467 & 42.37616 & 43.22368 & 44.0712 & 42.03715 & 37.29102 & 31.18885 \\
\hline Residential, & 1474.792 & 1463.225 & 1445.874 & 1474.792 & 1503.709 & 1434.307 & 1272.369 & 1064.164 \\
\hline & & & & & & 24 \\
\hline
\end{tabular}

\subsubsection{Objective Function and Constraints}

In the present study, the objective function for solving the EC problem is considered to reduce the cost of supplying energy demand. This objective function for 24-h study period is expressed by Equation (22). Additionally, to optimize the EC's objective function, the constraints related to the start-up cost of power plants and their authorized production range, specified in Equations (23)-(25), must be considered.

$$
\begin{gathered}
F_{\text {objective }}=\min \left\{\sum_{t=1}^{T}\left[\sum_{i=1}^{N_{c}} \text { carrier }_{i}^{t} \times \text { price }_{i}+\sum_{i=1}^{N_{g}} S C_{i}^{t}+\sum_{i=1}^{N_{g}} C_{i} u_{i}^{t}\right]\right\}, \\
S C_{i}^{t}=\left\{\begin{array}{c}
S C_{i}, u_{i}^{t}>u_{i}^{t-1}, \\
0, \text { else }
\end{array}\right. \\
P_{g_{i}}^{\min } \leq P_{g_{i}} \leq P_{g_{i}}^{\max }, \\
\sum_{i=1}^{N_{g}} P_{g_{i}}^{t}=\text { load }^{t} .
\end{gathered}
$$




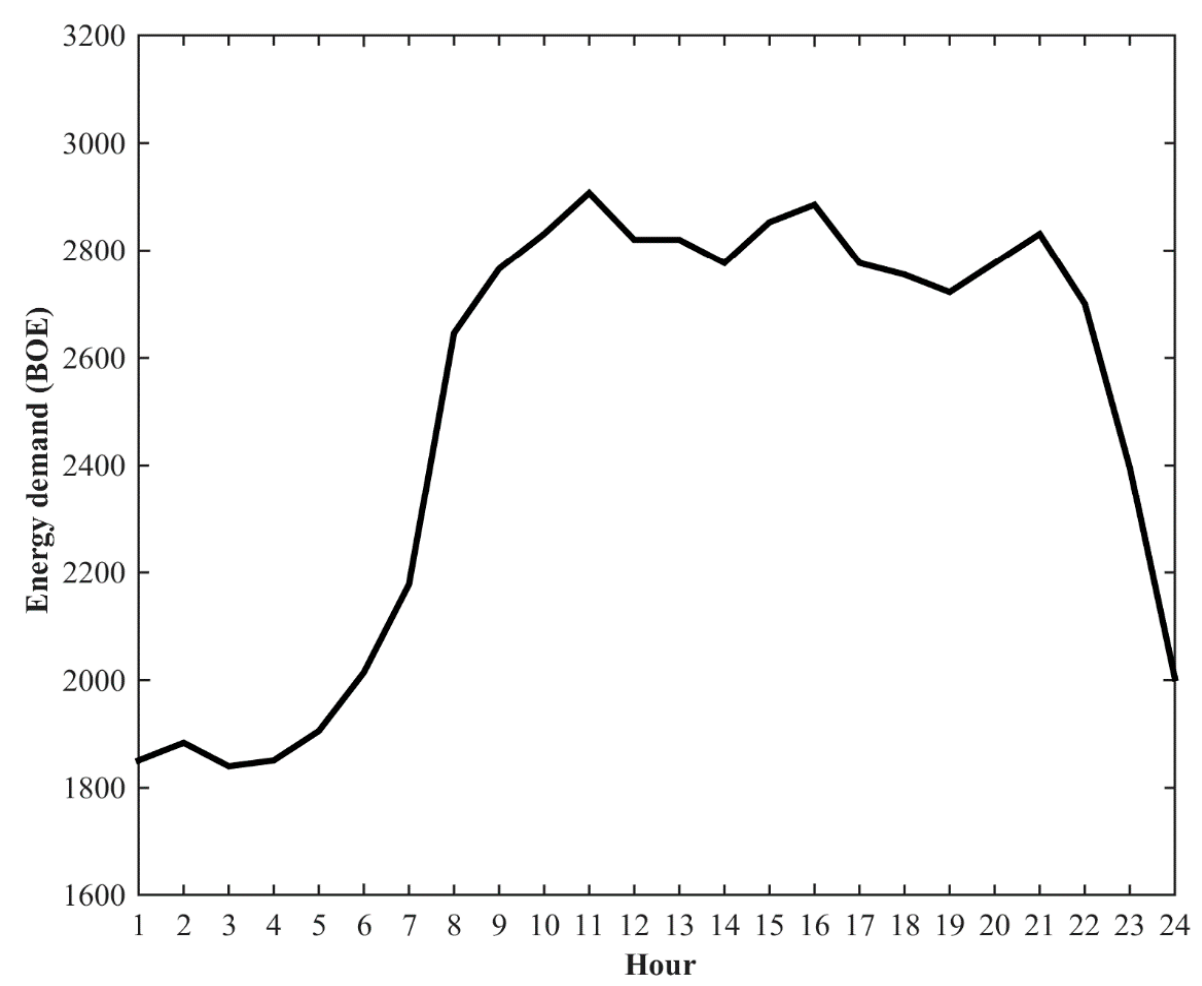

Figure 1. Energy demand profile.

\subsubsection{DPO Implementation to EC Problem}

The purpose of implementing the EC problem is to supply energy demand by determining the most appropriate use of energy carriers, considering technical and economical constraints. In the study of each hour of the 24-h period the first step, after the required energy conversions, was to determine possible combinations of power plants based on the required electrical energy demand. Therefore, all possible combinations of power plants are determined for each hour of the study period. The second step involved determining a suitable pattern for energy carrier use for the entire study period, as well as the optimal combination of power plants for each hour, based on the objective function and using the proposed optimization algorithm. This convenient pattern of energy carrier usage is actually the main output of EC problem.

The EC problem is coded in MATLAB and executed on a system with a quad-core $3.3 \mathrm{GHz}$ processor and 8 GB of RAM. The pseudo code of EC problem solution using DPO is specified in Algorithm 2.

\subsubsection{Results and Discussion}

The proposed DPO algorithm was implemented on the power system in order to achieve optimal results in an economical manner for the introduced energy commitment problem. The purpose of this operation is to reduce operating costs in order to supply energy demand. The important output of the energy commitment problem, the determination of the amount of different energy carriers for each hour of the study period, is specified in Table 5. The convergence curve (as an important indicator in the evaluation of optimization algorithms) of the implementation of the DPO on the EC problem is drawn in Figure 2. This curve shows the precise behavior of the algorithm while reaching the appropriate response, indicating the exploitation, exploration and power of the proposed algorithm. Another important output of the EC is to determine the appropriate pattern for the on and off state of power plant units for each hour of period of study to supply the electrical demand which is specified in Table 6. Additionally, the hourly production rate of the units during the study period, the output of the UC problem, is presented in Table 7. Finally, the import and export values of the energy carriers based 
on domestic production are specified in Table 8. According to this table, Petroleum $(399,217)$, Fuel oil $(29,054.3)$, Gas oil (478.824), Kerosene (297.468), and Coke gas (92.2559) are in the export section and liquid gas (2451.409), Gasoline (20,384.46), plane fuel (2934.952), natural gas (12,502.36), and coal (906.6509) are in the import section.

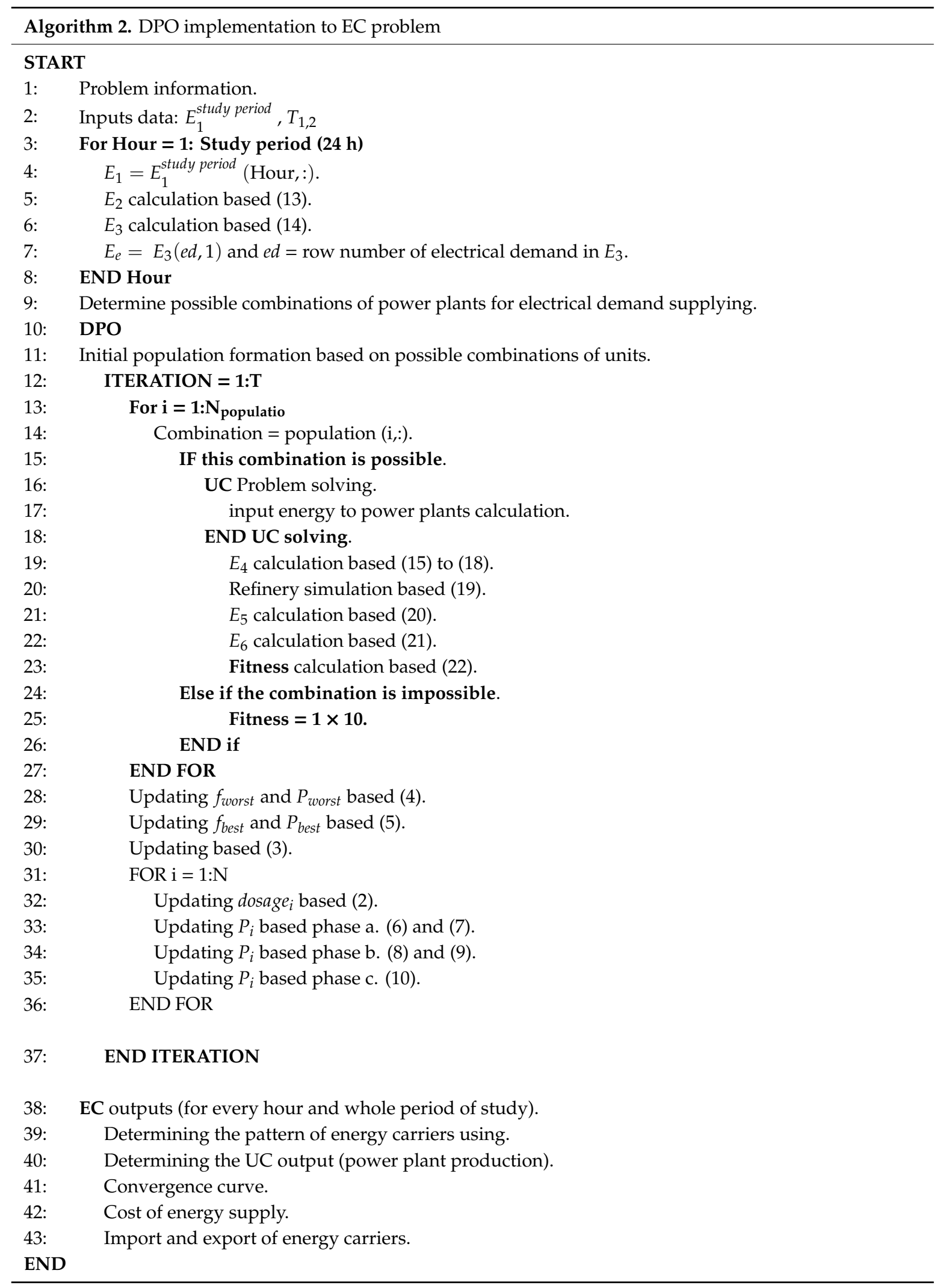


Table 5. The need of energy carriers (BOE).

\begin{tabular}{|c|c|c|c|c|c|c|c|c|}
\hline Hour & 1 & 2 & 3 & 4 & 5 & 6 & 7 & 8 \\
\hline Liquid Gas & 292.5897 & 297.7531 & 290.8686 & 292.5897 & 301.1953 & 318.4065 & 344.2232 & 418.2312 \\
\hline Fuel Oil & 1107.223 & 1133.425 & 1098.565 & 1114.323 & 1132.174 & 1206.242 & 1284.84 & 1520.263 \\
\hline Gas Oil & 1931.791 & 1963.236 & 1921.292 & 1930.419 & 1997.848 & 2110.83 & 2310.59 & 2837.866 \\
\hline Kerosene & 661.1897 & 672.8578 & 657.3004 & 661.1897 & 680.6365 & 719.53 & 777.8703 & 945.1124 \\
\hline Gasoline & 1694.256 & 1724.155 & 1684.29 & 1694.256 & 1744.087 & 1843.75 & 1993.243 & 2421.79 \\
\hline Plane Fuel & 90.86539 & 92.4689 & 90.33089 & 90.86539 & 93.5379 & 98.88293 & 106.9005 & 129.8841 \\
\hline Natural Gas & 7559.858 & 7691.954 & 7515.844 & 7564.33 & 7822.283 & 8285.097 & 9021.851 & $11,060.32$ \\
\hline Coke Gas & 45.5543 & 46.3582 & 45.28633 & 45.5543 & 46.89413 & 49.5738 & 53.59329 & 65.11585 \\
\hline Coal & 100.6855 & 102.4623 & 100.0932 & 100.6855 & 103.6468 & 109.5695 & 118.4535 & 143.921 \\
\hline Hour & 9 & 10 & 11 & 12 & 13 & 14 & 15 & 16 \\
\hline Liquid Gas & 437.1635 & 447.4902 & 459.538 & 445.7691 & 445.7691 & 438.8846 & 450.9324 & 456.0957 \\
\hline Fuel Oil & 1603.173 & 1653.536 & 1693.215 & 1651.406 & 1649.9 & 1612.975 & 1662.116 & 1685.183 \\
\hline Gas Oil & 2960.847 & 3026.316 & 3117.653 & 3013.492 & 3013.89 & 2971.341 & 3054.712 & 3091.246 \\
\hline Kerosene & 987.8952 & 1011.231 & 1038.457 & 1007.342 & 1007.342 & 991.7846 & 1019.01 & 1030.678 \\
\hline Gasoline & 2531.418 & 2591.216 & 2660.979 & 2581.249 & 2581.249 & 2541.385 & 2611.148 & 2641.047 \\
\hline Plane Fuel & 135.7636 & 138.9706 & 142.7121 & 138.4361 & 138.4361 & 136.2981 & 140.0396 & 141.6431 \\
\hline Natural Gas & $11,593.93$ & $11,881.31$ & 12249.3 & $11,829.5$ & $11,829.94$ & $11,641.09$ & 11982.27 & 12134.19 \\
\hline Coke Gas & 68.06348 & 69.67128 & 71.54705 & 69.40331 & 69.40331 & 68.33145 & 70.20721 & 71.01111 \\
\hline Coal & 150.4359 & 153.9895 & 158.1354 & 153.3973 & 153.3973 & 151.0282 & 155.1741 & 156.9509 \\
\hline Hour & 17 & 18 & 19 & 20 & 21 & 22 & 23 & 24 \\
\hline Liquid Gas & 438.8846 & 435.4424 & 430.279 & 438.8846 & 447.4902 & 426.8368 & 378.6455 & 316.6853 \\
\hline Fuel Oil & 1614.772 & 1593.371 & 1563.759 & 1619.075 & 1654.976 & 1550.461 & 1418.204 & 1209.212 \\
\hline Gas Oil & 2969.852 & 2950.352 & 2918.868 & 2967.727 & 3025.918 & 2894.268 & 2530.552 & 2097.053 \\
\hline Kerosene & 991.7846 & 984.0059 & 972.3378 & 991.7846 & 1011.231 & 964.5591 & 855.6573 & 715.6406 \\
\hline Gasoline & 2541.385 & 2521.452 & 2491.554 & 2541.385 & 2591.216 & 2471.621 & 2192.567 & 1833.783 \\
\hline Plane Fuel & 136.2981 & 135.2291 & 133.6256 & 136.2981 & 138.9706 & 132.5566 & 117.5905 & 98.34843 \\
\hline Natural Gas & $11,638.75$ & $11,546.77$ & $11,404.7$ & $11,636.14$ & $11,880.87$ & $11,306.04$ & 9885.869 & 8211.221 \\
\hline Coke Gas & 68.33145 & 67.79552 & 66.99162 & 68.33145 & 69.67128 & 66.45568 & 58.95262 & 49.30583 \\
\hline Coal & 151.0282 & 149.8437 & 148.0669 & 151.0282 & 153.9895 & 146.8823 & 130.2988 & 108.9772 \\
\hline
\end{tabular}

Table 6. Appropriate combination of units and total cost for energy supply.

\begin{tabular}{cccccccccccccc}
\hline Hour & 1 & 2 & 3 & 4 & 5 & 6 & 7 & 8 & 9 & 10 & 11 & 12 & \multirow{2}{*}{ Cost (\$) } \\
Combination & 10 & 10 & 10 & 11 & 13 & 17 & 19 & 22 & 23 & 22 & 26 & 22 & \\
\hline Hour & 13 & 14 & 15 & 16 & 17 & 18 & 19 & 20 & 21 & 22 & 23 & 24 & \\
Combination & 21 & 23 & 22 & 24 & 20 & 23 & 22 & 18 & 22 & 17 & 15 & 12 & $2.1153 \times 10^{7}$ \\
\hline
\end{tabular}


Table 7. Unit commitment (UC) result (MW).

\begin{tabular}{|c|c|c|c|c|c|c|c|c|c|c|c|c|c|}
\hline Hour & unit 1 & Unit 2 & unit 3 & unit 4 & unit 5 & unit 6 & unit 7 & unit 8 & unit 9 & unit 10 & unit 11 & unit 12 & unit 13 \\
\hline 1 & 400 & 400 & 350 & 197 & 197 & 197 & 65.66526 & 54.25 & 54.25 & 54.25 & 0 & 0 & 0 \\
\hline 2 & 400 & 400 & 350 & 197 & 197 & 197 & 100.4196 & 54.25 & 54.25 & 54.25 & 0 & 0 & 0 \\
\hline 3 & 400 & 400 & 350 & 197 & 197 & 196.8305 & 54.25 & 54.25 & 54.25 & 54.25 & 0 & 0 & 0 \\
\hline 4 & 400 & 400 & 350 & 197 & 197 & 183.4153 & 54.25 & 54.25 & 54.25 & 54.25 & 25 & 0 & 0 \\
\hline 5 & 400 & 400 & 350 & 197 & 197 & 191.3392 & 54.25 & 54.25 & 54.25 & 54.25 & 25 & 25 & 25 \\
\hline 6 & 400 & 400 & 350 & 197 & 197 & 197 & 103.6372 & 54.25 & 54.25 & 54.25 & 25 & 25 & 25 \\
\hline 7 & 400 & 400 & 350 & 197 & 197 & 197 & 155 & 155 & 67.90913 & 54.25 & 25 & 25 & 25 \\
\hline 8 & 400 & 400 & 350 & 197 & 197 & 197 & 155 & 155 & 155 & 155 & 100 & 100 & 100 \\
\hline 9 & 400 & 400 & 350 & 197 & 197 & 197 & 155 & 155 & 155 & 155 & 100 & 100 & 100 \\
\hline 10 & 400 & 400 & 350 & 197 & 197 & 197 & 155 & 155 & 155 & 155 & 100 & 100 & 100 \\
\hline 11 & 400 & 400 & 350 & 197 & 197 & 197 & 155 & 155 & 155 & 155 & 100 & 100 & 100 \\
\hline 12 & 400 & 400 & 350 & 197 & 197 & 197 & 155 & 155 & 155 & 155 & 100 & 100 & 100 \\
\hline 13 & 400 & 400 & 350 & 197 & 197 & 197 & 155 & 155 & 155 & 155 & 100 & 100 & 100 \\
\hline 14 & 400 & 400 & 350 & 197 & 197 & 197 & 155 & 155 & 155 & 155 & 100 & 100 & 100 \\
\hline 15 & 400 & 400 & 350 & 197 & 197 & 197 & 155 & 155 & 155 & 155 & 100 & 100 & 100 \\
\hline 16 & 400 & 400 & 350 & 197 & 197 & 197 & 155 & 155 & 155 & 155 & 100 & 100 & 100 \\
\hline 17 & 400 & 400 & 350 & 197 & 197 & 197 & 155 & 155 & 155 & 155 & 100 & 100 & 100 \\
\hline 18 & 400 & 400 & 350 & 197 & 197 & 197 & 155 & 155 & 155 & 155 & 100 & 100 & 100 \\
\hline 19 & 400 & 400 & 350 & 197 & 197 & 197 & 155 & 155 & 155 & 155 & 100 & 100 & 100 \\
\hline 20 & 400 & 400 & 350 & 197 & 197 & 197 & 155 & 155 & 155 & 155 & 100 & 100 & 100 \\
\hline 21 & 400 & 400 & 350 & 197 & 197 & 197 & 155 & 155 & 155 & 155 & 100 & 100 & 100 \\
\hline 22 & 400 & 400 & 350 & 197 & 197 & 197 & 155 & 155 & 155 & 155 & 100 & 100 & 100 \\
\hline 23 & 400 & 400 & 350 & 197 & 197 & 197 & 155 & 155 & 155 & 155 & 100 & 32.25505 & 25 \\
\hline 24 & 400 & 400 & 350 & 197 & 197 & 197 & 155 & 77.1024 & 54.25 & 54.25 & 25 & 25 & 0 \\
\hline
\end{tabular}


Table 7. Cont.

\begin{tabular}{|c|c|c|c|c|c|c|c|c|c|c|c|c|c|}
\hline Hour & unit 14 & unit 15 & unit 16 & unit 17 & unit 18 & unit 19 & unit 20 & unit 21 & unit 22 & unit 23 & unit 24 & unit 25 & unit 26 \\
\hline 1 & 0 & 0 & 0 & 0 & 0 & 0 & 0 & 0 & 0 & 0 & 0 & 0 & 0 \\
\hline 2 & 0 & 0 & 0 & 0 & 0 & 0 & 0 & 0 & 0 & 0 & 0 & 0 & 0 \\
\hline 3 & 0 & 0 & 0 & 0 & 0 & 0 & 0 & 0 & 0 & 0 & 0 & 0 & 0 \\
\hline 4 & 0 & 0 & 0 & 0 & 0 & 0 & 0 & 0 & 0 & 0 & 0 & 0 & 0 \\
\hline 5 & 0 & 0 & 0 & 0 & 0 & 0 & 0 & 0 & 0 & 0 & 0 & 0 & 0 \\
\hline 6 & 15.2 & 15.2 & 15.2 & 15.2 & 0 & 0 & 0 & 0 & 0 & 0 & 0 & 0 & 0 \\
\hline 7 & 15.2 & 15.2 & 15.2 & 15.2 & 4 & 4 & 0 & 0 & 0 & 0 & 0 & 0 & 0 \\
\hline 8 & 76 & 29.30535 & 15.2 & 15.2 & 4 & 4 & 4 & 4 & 2.4 & 0 & 0 & 0 & 0 \\
\hline 9 & 76 & 76 & 76 & 32.7381 & 4 & 4 & 4 & 4 & 2.4 & 2.4 & 0 & 0 & 0 \\
\hline 10 & 76 & 76 & 76 & 76 & 20 & 19.04687 & 4 & 4 & 0 & 0 & 0 & 0 & 0 \\
\hline 11 & 76 & 76 & 76 & 76 & 20 & 20 & 20 & 20 & 12 & 12 & 12 & 9.740442 & 2.4 \\
\hline 12 & 76 & 76 & 76 & 76 & 20 & 5.062077 & 4 & 4 & 2.4 & 0 & 0 & 0 & 0 \\
\hline 13 & 76 & 76 & 76 & 76 & 20 & 7.462077 & 4 & 4 & 0 & 0 & 0 & 0 & 0 \\
\hline 14 & 76 & 76 & 76 & 44.32289 & 4 & 4 & 4 & 4 & 2.4 & 2.4 & 0 & 0 & 0 \\
\hline 15 & 76 & 76 & 76 & 76 & 20 & 20 & 20 & 7.816464 & 2.4 & 0 & 0 & 0 & 0 \\
\hline 16 & 76 & 76 & 76 & 76 & 20 & 20 & 20 & 20 & 12 & 10.57085 & 2.4 & 0 & 0 \\
\hline 17 & 76 & 76 & 76 & 53.12289 & 4 & 4 & 4 & 0 & 0 & 0 & 0 & 0 & 0 \\
\hline 18 & 76 & 76 & 76 & 21.1533 & 4 & 4 & 4 & 4 & 2.4 & 2.4 & 0 & 0 & 0 \\
\hline 19 & 76 & 76 & 49.59892 & 15.2 & 4 & 4 & 4 & 4 & 2.4 & 0 & 0 & 0 & 0 \\
\hline 20 & 76 & 76 & 76 & 61.12289 & 4 & 0 & 0 & 0 & 0 & 0 & 0 & 0 & 0 \\
\hline 21 & 76 & 76 & 76 & 76 & 20 & 16.64687 & 4 & 4 & 2.4 & 0 & 0 & 0 & 0 \\
\hline 22 & 76 & 76 & 44.82932 & 15.2 & 0 & 0 & 0 & 0 & 0 & 0 & 0 & 0 & 0 \\
\hline 23 & 15.2 & 15.2 & 0 & 0 & 0 & 0 & 0 & 0 & 0 & 0 & 0 & 0 & 0 \\
\hline 24 & 0 & 0 & 0 & 0 & 0 & 0 & 0 & 0 & 0 & 0 & 0 & 0 & 0 \\
\hline
\end{tabular}



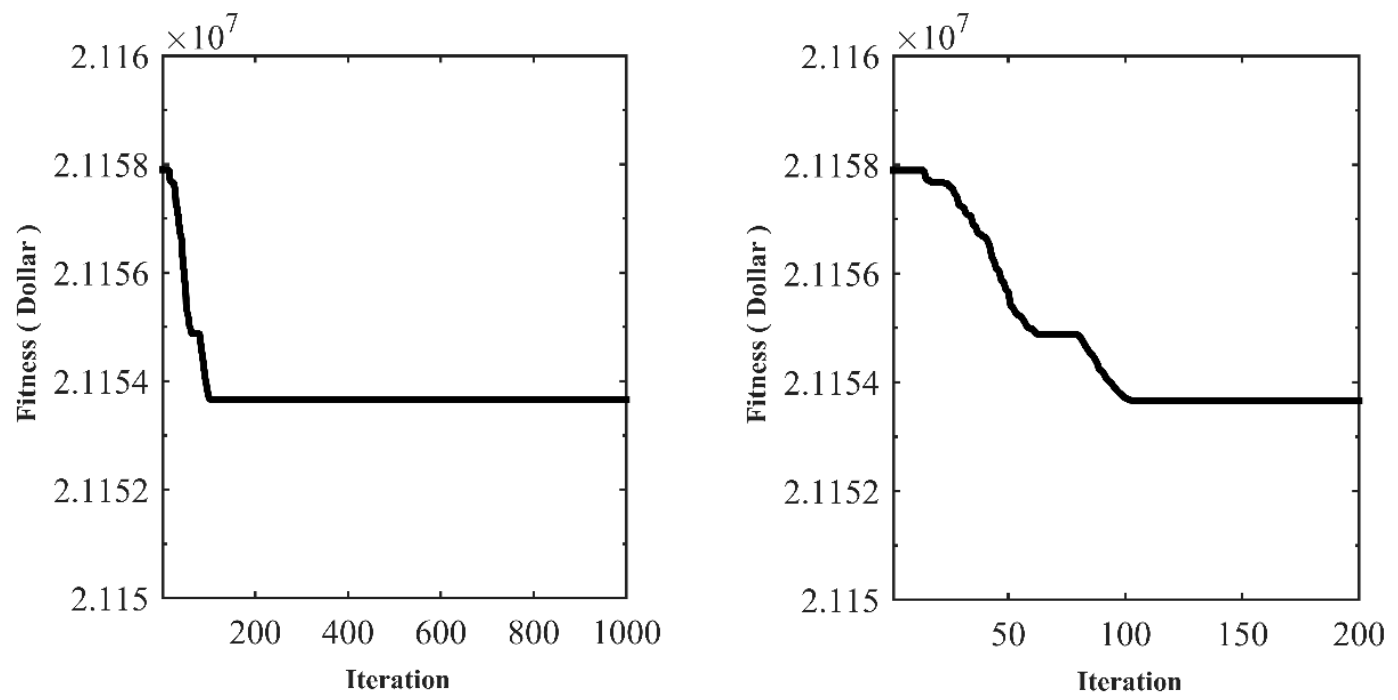

Figure 2. Convergence curve of doctor and patient optimization (DPO) on energy commitment (EC) solving.

Table 8. Import and export of carriers (BOE).

\begin{tabular}{ccc}
\hline Hour & Import & Export \\
\hline Petroleum & 0 & $-399,217$ \\
Liquid Gas & 2451.409 & 0 \\
Fuel Oil & 0 & $-29,054.3$ \\
Gas Oil & 0 & -478.824 \\
Kerosene & 0 & -297.468 \\
Gasoline & $20,384.46$ & 0 \\
Plane Fuel & $29,34.952$ & 0 \\
Natural Gas & $12,502.36$ & 0 \\
Coke Gas & 0 & -92.2559 \\
Coal & 906.6509 & 0 \\
\hline
\end{tabular}

\subsubsection{Comparison DPO and Other Algorithms on EC Problem}

In order to evaluate the performance of the proposed algorithm in solving the $\mathrm{EC}$, the other eight algorithms mentioned in this paper have been implemented on the EC problem. The results of this simulation are presented in Table 9. This table specifies the value of the objective function for each of the optimization algorithms. The proposed DPO algorithm is the best optimizer among the compared algorithms with the value of the objective function equal to $2.1153 \times 10^{7}$ Dollar. WOA with the value of the objective function $2.1739 \times 10^{7}$ Dollar, MPA with the value of the objective function $2.2365 \times 10^{7}$ Dollar, GWO with the value of the objective function $2.4257 \times 10^{7}$ Dollar, GOA with the value of the objective function $2.7592 \times 10^{7}$ Dollar, TLBO with the value of the objective function $3.2648 \times 10^{7}$ Dollar, GSA with the value of the objective function $6.7624 \times 10^{7}$ Dollar, PSO with The value of the target function is $5.2158 \times 10^{8}$ Dollar, and the GA with the value of the target function of $8.5146 \times 10^{8}$ Dollar are ranked second to ninth, respectively. Based on the results, the proposed algorithm has a high ability to solve the EC problem and is much more competitive than the other eight algorithms. 
Table 9. Results for DPO and other algorithms in EC problem.

\begin{tabular}{cccc}
\hline Algorithm & Avg (Dollar) & Std (Dollar) & Rank \\
\hline GA & $8.5146 \times 10^{8}$ & $2.6145 \times 10^{6}$ & 9 \\
PSO & $5.2158 \times 10^{8}$ & $1.2485 \times 10^{6}$ & 8 \\
GSA & $6.7624 \times 10^{7}$ & $5.2176 \times 10^{4}$ & 7 \\
TLBO & $3.2648 \times 10^{7}$ & $7.5423 \times 10^{3}$ & 6 \\
GOA & $2.7592 \times 10^{7}$ & $8.6427 \times 10^{2}$ & 5 \\
GWO & $2.4257 \times 10^{7}$ & $6.5654 \times 10^{2}$ & 4 \\
WOA & $2.1739 \times 10^{7}$ & $2.7865 \times 10^{2}$ & 2 \\
MPA & $2.2365 \times 10^{7}$ & $1.4552 \times 10^{2}$ & 3 \\
DPO & $2.1153 \times 10^{7}$ & 7.5142 & 1 \\
\hline
\end{tabular}

\section{Conclusions}

A new doctor and patient optimization (DPO) Algorithm was introduced based on a simulation of the patient treatment process. This treatment process has three phases including vaccination, drug administration, and surgery. To evaluate the effectiveness and performance of the DPO, two case studies were considered. In case study A, the performance and effectiveness of the proposed DPO algorithm was evaluated on a benchmark standard test function with twenty-three objective functions and compared to eight other algorithms. These results show the exploitation and exploration capacity of the proposed algorithm in solving optimization problems. In case study B, the proposed DPO algorithm was implemented on the energy commitment (EC) problem in a power system with twenty-six power plants and various energy sectors, including residential, commercial, public, industrial, transportation, and agriculture sectors. The purpose of the EC was to determine the appropriate pattern of use of energy carriers to supply energy demand and minimize operation costs considering the technical constraints. The DPO with high exploitation and exploration capacity was well implemented on the EC problem, and its results were determined including the appropriate pattern of use of energy carriers, proper composition, and production of power plants, as well as the amount of import and export of energy carriers.

In future works, the authors propose several study ideas, such as solving the EC problem using other optimization algorithms and techniques, creating a binary variant of the DPO which has an important potential contribution, and applying DPO to overcome many-objective real-life optimization problems, as well as multi-objective problems.

Author Contributions: Conceptualization, M.D., M.M., J.C.V. and J.M.G.; methodology, M.D.; software, M.D.; validation, R.A.R.-M., J.M.G., L.P.-A., and O.P.M.; formal analysis, J.M., R.A.R.-M., L.P.A., and O.P.M.; investigation, M.D., J.C.V. and O.P.M.; resources, R.A.R.-M.; data curation, R.A.R.-M.; writing-original draft preparation, M.D. and M.M.; writing-review and editing, J.M., J.C.V., O.P.M., L.P.-A., and R.A.R.-M.; visualization, M.D.; supervision, M.M.; project administration, M.D. and M.M.; funding acquisition, R.A.R.-M. All authors have read and agreed to the published version of the manuscript.

Funding: The current project was funded by Tecnologico de Monterrey and FEMSA Foundation (grant CAMPUSCITY project).

Conflicts of Interest: The authors declare no conflict of interest. The authors declare that they have no known competing financial interests or personal relationships that could have appeared to influence the work reported in this paper.

\section{Appendix A}

Tables A1-A7. 
Table A1. Unit information.

\begin{tabular}{|c|c|c|c|c|c|c|c|c|c|c|c|c|}
\hline \multirow{2}{*}{ Row. } & \multirow{2}{*}{ Power Plant } & \multicolumn{2}{|c|}{ Capacity of Unit (MW) } & \multirow{2}{*}{ Efficiency } & \multirow{2}{*}{$\begin{array}{c}\text { Constant } \\
\text { Cost }\end{array}$} & \multirow{2}{*}{ Priority } & \multirow{2}{*}{$\begin{array}{c}M U T \\
\text { (Hour) }\end{array}$} & \multirow{2}{*}{$\begin{array}{c}M D T \\
\text { (Hour) }\end{array}$} & \multirow{2}{*}{$\begin{array}{l}\text { Cold } \\
\text { Start }\end{array}$} & \multirow{2}{*}{$\begin{array}{c}\text { Initial } \\
\text { Conditions }\end{array}$} & \multirow{2}{*}{$\begin{array}{l}\text { Hot Start } \\
\text { (Dollar) }\end{array}$} & \multirow{2}{*}{$\begin{array}{c}\text { Cold Star } \\
\text { (Dollar) }\end{array}$} \\
\hline & & Min & Max & & & & & & & & & \\
\hline 1 & Thermal & 100 & 400 & 0.368 & 312 & 1 & 8 & -5 & 4 & 10 & 800 & 1500 \\
\hline 2 & Thermal & 100 & 400 & 0.345 & 310 & 2 & 8 & -5 & 4 & 10 & 775 & 1500 \\
\hline 3 & Combined Cycle & 140 & 350 & 0.455 & 177 & 3 & 8 & -5 & 4 & 10 & 725 & 1200 \\
\hline 4 & Thermal & 68.95 & 197 & 0.317 & 260 & 4 & 5 & -4 & 2 & 8 & 750 & 1300 \\
\hline 5 & Gas & 68.95 & 197 & 0.3 & 260 & 5 & 5 & -4 & 2 & 8 & 700 & 1100 \\
\hline 6 & Combined Cycle & 68.95 & 197 & 0.47 & 260 & 6 & 5 & -4 & 2 & 8 & 650 & 950 \\
\hline 7 & Thermal & 54.25 & 155 & 0.35 & 143 & 7 & 5 & -3 & 2 & 8 & 600 & 850 \\
\hline 8 & Gas & 54.25 & 155 & 0.25 & 143 & 8 & 5 & -3 & 2 & 8 & 550 & 900 \\
\hline 9 & Combined Cycle & 54.25 & 155 & 0.5 & 143 & 9 & 5 & -3 & 2 & -8 & 500 & 700 \\
\hline 10 & Thermal & 54.25 & 155 & 0.358 & 143 & 10 & 5 & -3 & 2 & -8 & 450 & 800 \\
\hline 11 & Thermal & 25 & 100 & 0.32 & 218 & 11 & 4 & -2 & 1 & -8 & 200 & 400 \\
\hline 12 & Gas & 25 & 100 & 0.27 & 218 & 12 & 4 & -2 & 1 & -8 & 600 & 900 \\
\hline 13 & Combined Cycle & 25 & 100 & 0.25 & 218 & 13 & 4 & -2 & 1 & -8 & 250 & 500 \\
\hline 14 & Gas & 15.2 & 76 & 0.3 & 81 & 14 & 3 & -2 & 1 & -8 & 400 & 600 \\
\hline 15 & Combined Cycle & 15.2 & 76 & 0.3 & 81 & 15 & 3 & -2 & 1 & -8 & 250 & 400 \\
\hline 16 & Thermal & 15.2 & 76 & 0.29 & 81 & 16 & 3 & -2 & 1 & -8 & 400 & 600 \\
\hline 17 & Thermal & 15.2 & 76 & 0.29 & 81 & 17 & 3 & -2 & 1 & -8 & 300 & 500 \\
\hline 18 & Thermal & 4 & 20 & 0.29 & 118 & 18 & 1 & -1 & 0 & -4 & 300 & 450 \\
\hline 19 & Combined Cycle & 4 & 20 & 0.291 & 118 & 19 & 1 & -1 & 0 & -4 & 200 & 350 \\
\hline 20 & Gas & 4 & 20 & 0.275 & 118 & 20 & 1 & -1 & 0 & -4 & 200 & 400 \\
\hline 21 & Gas & 4 & 20 & 0.27 & 118 & 21 & 1 & -1 & 0 & -1 & 150 & 300 \\
\hline 22 & Thermal & 2.4 & 12 & 0.26 & 24 & 22 & 1 & -1 & 0 & -3 & 50 & 200 \\
\hline 23 & Thermal & 2.4 & 12 & 0.25 & 24 & 23 & 1 & -1 & 0 & -2 & 100 & 250 \\
\hline 24 & Combined Cycle & 2.4 & 12 & 0.23 & 24 & 24 & 1 & -1 & 0 & -1 & 150 & 300 \\
\hline 25 & Combined Cycle & 2.4 & 12 & 0.22 & 24 & 25 & 1 & -1 & 0 & -2 & 100 & 200 \\
\hline 26 & Gas & 2.4 & 12 & 0.2 & 24 & 26 & 1 & -1 & 0 & -3 & 150 & 250 \\
\hline
\end{tabular}


Table A2. $T_{1,2}$ matrix.

\begin{tabular}{ccccccc}
\hline & $\begin{array}{c}\text { Residential, } \\
\text { Commercial } \\
\text { and Public }\end{array}$ & Industrial & Transportation & Agriculture & Other & Non-Energy \\
\hline Petroleum & 0 & 0 & 0 & 0 & 0 & 0 \\
Liquid gas & 0.051 & 0.013 & 0.01 & 0 & 0 & 0 \\
Fuel oil & 0.023 & 0.212 & 0.014 & 0 & 0 & 0 \\
Gas oil & 0.055 & 0.087 & 0.363 & 0.689 & 0 & 0 \\
Kerosene & 0.141 & 0.002 & 0 & 0.018 & 0 & 0 \\
Gasoline & 0.002 & 0.002 & 0.573 & 0.003 & 0 & 0 \\
Plane fuel & 0 & 0 & 0.031 & 0 & 0 & 0 \\
Other products & 0 & 0 & 0 & 0 & 0 & 0.402 \\
Natural gas & 0.564 & 0.521 & 0.007 & 0 & 0 & 0.497 \\
Coke gas & 0 & 0.021 & 0 & 0 & 0 & 0 \\
Coal & 0.0003 & 0 & 0 & 0 & 0 & 0.101 \\
Non-Commercial fuels & 0.064 & 0 & 0 & 0 & 0 & 0 \\
Electricity(power) & 0.102 & 0.142 & 0.0004 & 0.29 & 1 & 0 \\
\hline
\end{tabular}

Table A3. Matrix $T_{p}$.

\begin{tabular}{cc}
\hline Petroleum & 0 \\
liquid Gas & 0.032 \\
Fuel Oil & 0.293 \\
Gas Oil & 0.293 \\
Kerosene & 0.099 \\
Gasoline & 0.157 \\
plane Fuel & 0 \\
Other Products & 0.058 \\
Natural Gas & 0 \\
Coke Gas & 0 \\
Coal & 0 \\
Non-Commercial Fuels & 0 \\
Electricity(power) & 0 \\
\hline
\end{tabular}

Table A4. Conversion matrix input energy to fuel power plants.

\begin{tabular}{cccc}
\hline Power Plant & Thermal Unit & Combined Cycle Unit & Gas Unit \\
\hline Fuel Oil & 0.254 & 0 & 0 \\
Gas Oil & 0.003 & 0.082 & 0.166 \\
Natural Gas & 0.743 & 0.918 & 0.834 \\
\hline
\end{tabular}

Table A5. Domestic supplies of energy carriers.

\begin{tabular}{ccc}
\hline Row & Energy Carrier & Energy (Boe) \\
\hline 1 & Petroleum & $25,747.64405$ \\
2 & liquid Gas & 0 \\
3 & Fuel Oil & 0 \\
4 & Gas Oil & 0 \\
5 & Kerosene & 0 \\
6 & Gasoline & 0 \\
7 & Plane Fuel & 0 \\
8 & Other Products & 0 \\
9 & Natural Gas & 9861.294929 \\
10 & Coke Gas & 65.15249127 \\
11 & Coal & 97.72873691 \\
12 & Non-Commercial Fuels & 394.0174472 \\
13 & Electricity(power) & 0 \\
\hline
\end{tabular}


Table A6. Heating value [63] and energy rates [64].

\begin{tabular}{ccc}
\hline Energy Carrier & Heating Value & Energy Rates \\
\hline Petroleum & $38.5 \frac{\mathrm{MJ}}{\mathrm{Lit}}$ & 48 dollar/boe \\
Liquid Gas & $46.15 \frac{\mathrm{MJ}}{\mathrm{Kg}}$ & $374 \mathrm{dollar} /$ tone \\
Fuel Oil & $42.18 \frac{\mathrm{MJ}}{\mathrm{Kg}}$ & $180 \mathrm{dollar} /$ tone \\
Gas Oil & $43.38 \frac{\mathrm{MJ}}{\mathrm{Kg}}$ & $350 \mathrm{dollar} /$ tone \\
Kerosene & $43.32 \frac{\mathrm{MJ}}{\mathrm{Kg}}$ & 500 dollar/tone \\
Gasoline & $44.75 \frac{\mathrm{MJ}}{\mathrm{Kg}}$ & 450 dollar/tone \\
Plane Fuel & $45.03 \frac{\mathrm{MJ}}{\mathrm{Kg}}$ & 555 dollar/tone \\
Natural Gas & $39 \frac{\mathrm{MJ}}{\mathrm{m}}$ & 237 dollar/le3m \\
Coke Gas & $16.9 \frac{\mathrm{MJ}}{\mathrm{Kg}}$ & 157 dollar/tone \\
Coal & $26.75 \frac{\mathrm{MJ}}{\mathrm{Kg}}$ & 61 dollar/tone \\
\hline
\end{tabular}

Table A7. Matrix $\mathrm{T}_{23}$.

\begin{tabular}{cccccccccccccc}
\hline Petroleum & 1 & 0 & 0 & 0 & 0 & 0 & 0 & 0 & 0 & 0 & 0 & 0 & 0 \\
Liquid Gas & 0 & 1 & 0 & 0 & 0 & 0 & 0 & 0 & 0 & 0 & 0 & 0 & 0 \\
Fuel Oil & 0 & 0 & 1 & 0 & 0 & 0 & 0 & 0 & 0 & 0 & 0 & 0 & 0 \\
Gas Oil & 0 & 0 & 0 & 1 & 0 & 0 & 0 & 0 & 0 & 0 & 0 & 0 & 0 \\
Kerosene & 0 & 0 & 0 & 0 & 1 & 0 & 0 & 0 & 0 & 0 & 0 & 0 & 0 \\
Gasoline & 0 & 0 & 0 & 0 & 0 & 1 & 0 & 0 & 0 & 0 & 0 & 0 & 0 \\
plane Fuel & 0 & 0 & 0 & 0 & 0 & 0 & 1 & 0 & 0 & 0 & 0 & 0 & 0 \\
Other Products & 0 & 0 & 0 & 0 & 0 & 0 & 0 & 1 & 0 & 0 & 0 & 0 & 0 \\
Natural Gas & 0 & 0 & 0 & 0 & 0 & 0 & 0 & 0 & 1.1601 & 0 & 0 & 0 & 0 \\
Coke Gas & 0 & 0 & 0 & 0 & 0 & 0 & 0 & 0 & 0 & 1 & 0 & 0 & 0 \\
Coal & 0 & 0 & 0 & 0 & 0 & 0 & 0 & 0 & 0 & 0 & 1 & 0 & 0 \\
Non-Commercial Fuels & 0 & 0 & 0 & 0 & 0 & 0 & 0 & 0 & 0 & 0 & 0 & 1 & 0 \\
Electricity(power) & 0 & 0 & 0 & 0 & 0 & 0 & 0 & 0 & 0 & 0 & 0 & 0 & 1.3158 \\
\hline
\end{tabular}

\section{Appendix B}

Tables A8-A10.

Table A8. Unimodal test functions.

\begin{tabular}{cc}
\hline$[-100,100]^{m}$ & $F_{1}(x)=\sum_{i=1}^{m} x_{i}^{2}$ \\
{$[-10,10]^{m}$} & $F_{2}(x)=\sum_{i=1}^{m}\left|x_{i}\right|+\prod_{i=1}^{m}\left|x_{i}\right|$ \\
{$[-100,100]^{m}$} & $F_{3}(x)=\sum_{i=1}^{m}\left(\sum_{j=1}^{i} x_{i}\right)^{2}$ \\
{$[-100,100]^{m}$} & $F_{4}(x)=\max \left\{\left|x_{i}\right|, 1 \leq i \leq m\right\}$ \\
{$[-100,100]^{m}$} & $\left.F_{5}(x)=\sum_{i=1}^{m-1}\left[100\left(x_{i+1}-x_{i}^{2}\right)^{2}+\left(x_{i}-1\right)^{2}\right)\right]$ \\
{$[-100,100]^{m}$} & $F_{6}(x)=\sum_{i=1}^{m}\left(\left[x_{i}+0.5\right]\right)^{2}$ \\
{$[-1.28,1.28]^{m}$} & $F_{7}(x)=\sum_{i=1}^{m} i x_{i}^{4}+\operatorname{random}(0,1)$ \\
\hline
\end{tabular}


Table A9. Multimodal test functions.

\begin{tabular}{|c|c|}
\hline$[-500,500]^{m}$ & $F_{8}(x)=\sum_{i=1}^{m}-x_{i} \sin \left(\sqrt{\left|x_{i}\right|}\right)$ \\
\hline$[-5.12,5.12]^{m}$ & $F_{9}(x)=\sum_{i=1}^{m}\left[x_{i}^{2}-10 \cos \left(2 \pi x_{i}\right)+10\right]$ \\
\hline$[-32,32]^{m}$ & $F_{10}(x)=-20 \exp \left(-0.2 \sqrt{\frac{1}{m}} \sum_{i=1}^{m} x_{i}^{2}\right)-\exp \left(\frac{1}{m} \sum_{i=1}^{m} \cos \left(2 \pi x_{i}\right)\right)+20+e$ \\
\hline$[-600,600]^{m}$ & $F_{11}(x)=\frac{1}{4000} \sum_{i=1}^{m} x_{i}^{2}-\prod_{i=1}^{m} \cos \left(\frac{x_{i}}{\sqrt{i}}\right)+1$ \\
\hline$[-50,50]^{m}$ & $\begin{array}{l}F_{12}(x)=\frac{\pi}{m}\left\{10 \sin \left(\pi y_{1}\right)+\sum_{i=1}^{m}\left(y_{i}-1\right)^{2}\left[1+10 \sin ^{2}\left(\pi y_{i+1}\right)\right]+\left(y_{n}-1\right)^{2}\right\}+\sum_{i=1}^{m} u\left(x_{i}, 10,100,4\right) \\
u\left(x_{i}, a, i, n\right)=\left\{\begin{array}{lc}k\left(x_{i}-a\right)^{n} & x_{i}>-a \\
0 & -a<x_{i}<a \\
k\left(-x_{i}-a\right)^{n} & x_{i}<-a\end{array}\right.\end{array}$ \\
\hline$[-50,50]^{m}$ & $\begin{array}{l}F_{13}(x)=0.1\left\{\sin ^{2}\left(3 \pi x_{1}\right)+\sum_{i=1}^{m}\left(x_{i}-1\right)^{2}\left[1+\sin ^{2}\left(3 \pi x_{i}+1\right)\right]+\left(x_{n}-1\right)^{2}\left[1+\sin ^{2}\left(2 \pi x_{m}\right)\right]\right\}+ \\
\sum_{i=1}^{m} u\left(x_{i}, 5,100,4\right)\end{array}$ \\
\hline
\end{tabular}

Table A10. Multimodal test functions with fixed dimension.

\begin{tabular}{|c|c|}
\hline$[-65.53,65.53]^{2}$. & $F_{14}(x)=\left(\frac{1}{500}+\sum_{j=1}^{25} \frac{1}{j+\sum_{i=1}^{2}\left(x_{i}-a_{i j}\right)^{6}}\right)^{-1}$ \\
\hline$[-5,5]^{4}$ & $F_{15}(x)=\sum_{i=1}^{11}\left[a_{i}-\frac{x_{1}\left(b_{i}^{2}+b_{i} x_{2}\right)}{b_{i}^{2}+b_{i} x_{3}+x_{4}}\right]^{2}$ \\
\hline$[-5,5]^{2}$ & $F_{16}(x)=4 x_{1}^{2}-2.1 x_{1}^{4}+\frac{1}{3} x_{1}^{6}+x_{1} x_{2}-4 x_{2}^{2}+4 x_{2}^{4}$ \\
\hline$[-5,10] \times[0,15]$ & $F_{17}(x)=\left(x_{2}-\frac{5.1}{4 \pi^{2}} x_{1}^{2}+\frac{5}{\pi} x_{1}-6\right)^{2}+10\left(1-\frac{1}{8 \pi}\right) \cos x_{1}+10$ \\
\hline$[-5,5]^{2}$ & $\begin{array}{c}F_{18}(x)=\left[1+\left(x_{1}+x_{2}+1\right)^{2}\left(19-14 x_{1}+3 x_{1}^{2}-14 x_{2}+6 x_{1} x_{2}+3 x_{2}^{2}\right)\right] \times \\
{\left[30+\left(2 x_{1}-3 x_{2}\right)^{2} \times\left(18-32 x_{1}+12 x_{1}^{2}+48 x_{2}-36 x_{1} x_{2}+27 x_{2}^{2}\right)\right]}\end{array}$ \\
\hline$[0,1]^{3}$ & $F_{19}(x)=-\sum_{i=1}^{4} c_{i} \exp \left(-\sum_{j=1}^{3} a_{i j}\left(x_{j}-P_{i j}\right)^{2}\right)$ \\
\hline$[0,1]^{6}$ & $F_{20}(x)=-\sum_{i=1}^{4} c_{i} \exp \left(-\sum_{j=1}^{6} a_{i j}\left(x_{j}-P_{i j}\right)^{2}\right)$ \\
\hline$[0,10]^{4}$ & $F_{21}(x)=-\sum_{i=1}^{5}\left[\left(X-a_{i}\right)\left(X-a_{i}\right)^{T}+6 c_{i}\right]^{-1}$ \\
\hline$[0,10]^{4}$ & $F_{22}(x)=-\sum_{i=1}^{7}\left[\left(X-a_{i}\right)\left(X-a_{i}\right)^{T}+6 c_{i}\right]^{-1}$ \\
\hline$[0,10]^{4}$ & $F_{23}(x)=-\sum_{i=1}^{10}\left[\left(X-a_{i}\right)\left(X-a_{i}\right)^{T}+6 c_{i}\right]^{-1}$ \\
\hline
\end{tabular}

\section{References}

1. IEA. Energy Statistics Manual; OECD Publishing: Paris, France, 2004.

2. Dehghani, M.; Montazeri, Z.; Ehsanifar, A.; Seifi, A.R.; Ebadi, J.M.; Grechko, O. Planning of energy carriers based on final energy consumption using dynamic programming and particle swarm optimization. Elec. Eng. Electromech. 2018, 5, 62-71. [CrossRef]

3. Dehghani, M.; Montazeri, Z.; Malik, O. Energy commitment: A planning of energy carrier based on energy consumption. Электротехника и Электромеханика 2019, 6. [CrossRef]

4. Smith, D.K.; Bertsekas, D.P. Nonlinear Programming. J. Oper. Res. Soc. 1997, 48, 334. [CrossRef]

5. Bellman, R. Dynamic programming. Science 1966, 153, 34-37. [CrossRef] [PubMed]

6. Frank, M.; Wolfe, P. An algorithm for quadratic programming. Nav. Res. Logist. Q. 1956, 3, 95-110. [CrossRef]

7. Mirjalili, S.; Mirjalili, S.M.; Lewis, A. Grey Wolf Optimizer. Adv. Eng. Softw. 2013, 69, 46-61. [CrossRef]

8. Yazdani, M.; Jolai, F. Lion Optimization Algorithm (LOA): A nature-inspired metaheuristic algorithm. J. Comput. Des. Eng. 2015, 3, 24-36. [CrossRef] 
9. Dorigo, M.; Stützle, T. Ant Colony Optimization: Overview and Recent Advances. Handb. Metaheuristics. Int. Ser. Oper. Res. Manag. Sci. 2019, 272, 311-351.

10. Dehghani, M.; Mardaneh, M.; Malik, O.P.; NouraeiPour, S.M. DTO: Donkey Theorem Optimization. In Proceedings of the 2019 27th Iranian Conference on Electrical Engineering (ICEE), Yazd, Iran, 30 April-2 May 2019; Institute of Electrical and Electronics Engineers: New Jersey, NJ, USA, 2019; pp. 1855-1859.

11. Barry, J.; Thron, C. A Computational Physics-Based Algorithm for Target Coverage Problems. In Advances in Nature-Inspired Computing and Applications; Shandilya, S., Nagar, A., Eds.; Springer: Cham, Germany, 2019; pp. 269-290.

12. Dehghani, M.; Montazeri, Z.; Dehghani, A.; Seifi, A. Spring search algorithm: A new meta-heuristic optimization algorithm inspired by Hooke's law. In Proceedings of the 4th International Conference on Knowledge-Based Engineering and Innovation (KBEI), Berlin, Germany, 21-23 December 2017; pp. 0210-0214.

13. Eskandar, H.; Sadollah, A.; Bahreininejad, A.; Hamdi, M. Water cycle algorithm-A novel metaheuristic optimization method for solving constrained engineering optimization problems. Comput. Struct. 2012, 110, 151-166. [CrossRef]

14. Rashedi, E.; Nezamabadi-Pour, H.; Saryazdi, S. GSA: A Gravitational Search Algorithm. Inf. Sci. 2009, 179, 2232-2248. [CrossRef]

15. Kirkpatrick, S.; Gelatt, J.C.D.; Vecchi, M.P. Optimization by Simulated Annealing. World Sci. Lect. Notes Phys. 1986, 220, 339-348. [CrossRef]

16. Moghaddam, F.F.; Moghaddam, R.F.; Cheriet, M. Curved space optimization: A random search based on general relativity theory. arXiv 2012, arXiv:1208.2214.

17. Shah-Hosseini, H. Principal components analysis by the galaxy-based search algorithm: A novel metaheuristic for continuous optimisation. Int. J. Comput. Sci. Eng. 2011, 6, 132. [CrossRef]

18. Alatas, B. ACROA: Artificial Chemical Reaction Optimization Algorithm for global optimization. Expert Syst. Appl. 2011, 38, 13170-13180. [CrossRef]

19. Formato, R.A. Central Force Optimization: A New Nature Inspired Computational Framework for Multidimensional Search and Optimization. In Nature Inspired Cooperative Strategies for Optimization (NICSO 2007); Krasnogon, N., Nicosia, V., Pavone, M., Pelta, D.A., Eds.; Springer Science and Business Media LLC: Berlin, Germany, 2008; Volume 129, pp. 221-238.

20. Du, H.; Wu, X.; Zhuang, J. Small-World Optimization Algorithm for Function Optimization. In Proceedings of the Computer Vision, Xi'an, China, 24-28 September 2006; Springer Science and Business Media LLC: Berlin, Germany, 2006; pp. 264-273.

21. Bansal, J.C. Particle Swarm Optimization. In Evolutionary and Swarm Intelligence Algorithms; Springer Science and Business Media LLC: Berlin, Germany, 2018; pp. 11-23.

22. Saremi, S.; Mirjalili, S.; Lewis, A. Grasshopper Optimisation Algorithm: Theory and application. Adv. Eng. Softw. 2017, 105, 30-47. [CrossRef]

23. Faramarzi, A.; Heidarinejad, M.; Mirjalili, S.; Gandomi, A.H. Marine Predators Algorithm: A nature-inspired metaheuristic. Expert Syst. Appl. 2020, 152, 113377. [CrossRef]

24. Gandomi, A.H.; Yang, X.-S.; Alavi, A.H. Cuckoo search algorithm: A metaheuristic approach to solve structural optimization problems. Eng. Comput. 2011, 29, 17-35. [CrossRef]

25. Karaboga, D.; Basturk, B. Artificial Bee Colony (ABC) Optimization Algorithm for Solving Constrained Optimization Problems. Comput. Vis. 2007, 4529, 789-798. [CrossRef]

26. Mirjalili, S. The Ant Lion Optimizer. Adv. Eng. Softw. 2015, 83, 80-98. [CrossRef]

27. Mirjalili, S.; Lewis, A. The Whale Optimization Algorithm. Adv. Eng. Softw. 2016, 95, 51-67. [CrossRef]

28. Yang, X.-S. A New Metaheuristic Bat-Inspired Algorithm. In Nature Inspired Cooperative Strategies for Optimization (NICSO 2010); Krasnogon, N., Nicosia, V., Pavone, M., Pelta, D.A., Eds.; Springer Science and Business Media LLC: Berlin, Germany, 2010; Volume 284, pp. 65-74.

29. Castillo, O.; Aguilar, L.T. Genetic Algorithms. In Type-2 Fuzzy Logic. in Control. of Nonsmooth Systems; Springer: Cham, Switzerland, 2019; pp. 23-39.

30. Beyer, H.-G.; Schwefel, H.-P. Evolution strategies-A comprehensive introduction. Nat. Comput. 2002, 1, 3-52. [CrossRef]

31. Storn, R.; Price, K. Differential Evolution-A Simple and Efficient Adaptive Scheme for Global Optimization Over Continuous Spaces; Berkeley: Berkeley, CA, USA, 1995. 
32. Mirjalili, S. BiogeographyB-Based Optimisation. In Evolutionary Algorithms and Neural Networks; Krasnogon, N., Nicosia, V., Pavone, M., Pelta, D.A., Eds.; Springer Science and Business Media LLC: Berlin, Germany, 2018; pp. 57-72.

33. Koza, J.R. Genetic programming: A Paradigm for Genetically Breeding Populations of Computer Programs to Solve Problems; Stanford University, Department of Computer Science: Stanford, CA, USA, 1990.

34. Dehghani, M.; Montazeri, Z.; Malik, O.P. DGO: Dice Game Optimizer. Gazi Univ. J. Sci. 2019, 32, 871-882. [CrossRef]

35. Dehghani, M.; Montazeri, Z.; Malik, O.P.; Ehsanifar, A.; Dehghani, A. 0OSA: Orientation Search Algorithm. Int. J. Ind. Elect. Control. Optim. 2019, 2, 99-112.

36. Dehghani, M.; Shiraz University of Technology; Montazeri, Z.; Malik, O.; Givi, H.; Guerrero, J. University of Calgary; University of Shahreza; Aalborg University Shell Game Optimization: A Novel Game-Based Algorithm. Int. J. Intell. Eng. Syst. 2020, 13, 10. [CrossRef]

37. Wood, A.J.; Wollenberg, B.F. Power Generation, Operation, and Control; John Wiley \& Sons: New Jersey, NJ, USA, 2012.

38. Abdou, I.; Tkiouat, M. Unit Commitment Problem in Electrical Power System: A Literature Review. Int. J. Electr. Comput. Eng. 2018, 8, 1357-1372. [CrossRef]

39. Gögler, P.; Dorfner, M.; Hamacher, T. Hybrid Robust/Stochastic Unit Commitment With Iterative Partitions of the Continuous Uncertainty Set. Front. Energy Res. 2018, 6, 71. [CrossRef]

40. Tiwari, S.; Dwivedi, B.; Dave, M. A two stage solution methodology for deterministic unit commitment problem. In Proceedings of the 2016 IEEE Uttar Pradesh Section International Conference on Electrical, Computer and Electronics Engineering (UPCON), Varanasi, India, 9-11 December 2016; pp. 317-322.

41. Del Nozal, A.R.; Tapia, A.; Alvarado-Barrios, L.; Reina, D.G. Application of Genetic Algorithms for Unit Commitment and Economic Dispatch Problems in Microgrids. In Nature Inspired Computing for Data Science; Krasnogon, N., Nicosia, V., Pavone, M., Pelta, D.A., Eds.; Springer Science and Business Media LLC: Berlin, Germany, 2019; pp. 139-167.

42. Gutiérrez-Alcaraz, G.; Hinojosa, V. Using Generalized Generation Distribution Factors in a MILP Model to Solve the Transmission-Constrained Unit Commitment Problem. Energies 2018, 11, 2232. [CrossRef]

43. Hussein, B.M.; Jaber, A.S. Unit commitment based on modified firefly algorithm. Meas. Control. 2020, 53, 320-327. [CrossRef]

44. Dhaliwal, J.S.; Dhillon, J.S. Profit based unit commitment using memetic binary differential evolution algorithm. Appl. Soft Comput. 2019, 81, 105502. [CrossRef]

45. Nikzad, H.R.; Abdi, H. A robust unit commitment based on GA-PL strategy by applying TOAT and considering emission costs and energy storage systems. Electr. Power Syst. Res. 2020, 180, 106154. [CrossRef]

46. Hussain, A.N.; Ismail, A.A. Operation cost reduction in unit commitment problem using improved quantum binary PSO algorithm. Int. J. Electr. Comput. Eng. 2020, 10, 1149-1155. [CrossRef]

47. Strikanth, R.K.; Panwar, L.; Panigrahi, B.K.; Kumar, R. Binary whale optimization algorithm: A new metaheuristic approach for profit-based unit commitment problems in competitive electricity markets. Eng. Optim. 2018, 51, 369-389. [CrossRef]

48. Panwar, L.K.; Reddy, S.; Verma, A.; Panigrahi, B.K.; Kumar, R. Binary Grey Wolf Optimizer for large scale unit commitment problem. Swarm Evol. Comput. 2018, 38, 251-266. [CrossRef]

49. Ebrahimi, J.; Hosseinian, S.H.; Gharehpetian, G.B. Unit Commitment Problem Solution Using Shuffled Frog Leaping Algorithm. IEEE Trans. Power Syst. 2010, 26, 573-581. [CrossRef]

50. Jo, K.-H.; Kim, M.-K. Improved Genetic Algorithm-Based Unit Commitment Considering Uncertainty Integration Method. Energies 2018, 11, 1387. [CrossRef]

51. Simopoulos, D.; Kavatza, S.; Vournas, C. Reliability Constrained Unit Commitment Using Simulated Annealing. Ieee Trans. Power Syst. 2006, 21, 1699-1706. [CrossRef]

52. Carrión, M.; Zarate-Minano, R.; Domínguez, R. A Practical Formulation for Ex-Ante Scheduling of Energy and Reserve in Renewable-Dominated Power Systems: Case Study of the Iberian Peninsula. Energies 2018, 11, 1939. [CrossRef]

53. Li, J.; Niu, D.; Wu, M.; Wang, Y.; Li, F.; Dong, H. Research on Battery Energy Storage as Backup Power in the Operation Optimization of a Regional Integrated Energy System. Energies 2018, 11, 2990. [CrossRef]

54. Dominković, D.F.; Stark, G.; Hodge, B.-M.; Pedersen, A.S. Integrated Energy Planning with a High Share of Variable Renewable Energy Sources for a Caribbean Island. Energies 2018, 11, 2193. [CrossRef] 
55. Kaur, S.; Awasthi, L.K.; Sangal, A.; Dhiman, G. Tunicate Swarm Algorithm: A new bio-inspired based metaheuristic paradigm for global optimization. Eng. Appl. Artif. Intell. 2020, 90, 103541. [CrossRef]

56. Dhiman, G.; Garg, M.; Nagar, A.K.; Kumar, V.; Dehghani, M. A Novel Algorithm for Global Optimization: Rat Swarm Optimizer. J. Ambient Int. Human. Comp. 2020, 11, 1868-5145.

57. Digalakis, J.; Margaritis, K.G. On benchmarking functions for genetic algorithms. Int. J. Comput. Math. 2001, 77, 481-506. [CrossRef]

58. Wang, G.; Gandomi, A.H.; Yang, X.-S.; Alavi, A.H. A novel improved accelerated particle swarm optimization algorithm for global numerical optimization. Eng. Comput. 2014, 31, 1198-1220. [CrossRef]

59. Yang, X.-S. Firefly algorithm, stochastic test functions and design optimisation. Int. J. Bio-Inspired Comput. 2010, 2, 78. [CrossRef]

60. Mirjalili, S. Genetic Algorithm. In Evolutionary Algorithms and Neural Networks; Krasnogon, N., Nicosia, V., Pavone, M., Pelta, D.A., Eds.; Springer: Berlin, Germany, 2019; pp. 43-55.

61. Mirjalili, S. Optimisation. In Evolutionary Algorithms and Neural Networks; Krasnogon, N., Nicosia, V., Pavone, M., Pelta, D.A., Eds.; Springer: Berlin, Germany, 2019; pp. 15-31.

62. Rao, R.V.; Savsani, V.J.; Vakharia, D. Teaching-learning-based optimization: A novel method for constrained mechanical design optimization problems. Comput. Des. 2011, 43, 303-315. [CrossRef]

63. Birol, F. International Energy Agency. Global Energy Review Report; IEA: Paris, France, 2004; pp. 1-50.

64. U.S. Energy Information Administration (EIA). Available online: http://www.eia.gov (accessed on 12 August 2020).

(C) 2020 by the authors. Licensee MDPI, Basel, Switzerland. This article is an open access article distributed under the terms and conditions of the Creative Commons Attribution (CC BY) license (http://creativecommons.org/licenses/by/4.0/). 